\title{
From the shape of the vertical profile of in vivo fluorescence to Chlorophyll- $a$ concentration
}

\author{
A. Mignot, H. Claustre, F. D'Ortenzio, X. Xing, A. Poteau, and J. Ras \\ CNRS, UMR7093, Laboratoire d'Océanographie de Villefranche, 06230 Villefranche-sur-Mer, France \\ Université Pierre et Marie Curie-Paris 6, UMR7093, Laboratoire d'Océanographie de Villefranche, 06230 \\ Villefranche-sur-Mer, France
}

Received: 11 March 2011 - Published in Biogeosciences Discuss.: 7 April 2011

Revised: 21 July 2011 - Accepted: 12 August 2011 - Published: 31 August 2011

\begin{abstract}
In vivo fluorescence of Chlorophyll- $a(\mathrm{Chl}-a)$ is a potentially useful property to study the vertical distribution of phytoplankton biomass. However the technique is presently not fully exploited as it should be, essentially because of the difficulties in converting the fluorescence signal into an accurate Chl- $a$ concentration. These difficulties arise noticeably from natural variations in the Chl- $a$ fluorescence relationship, which is under the control of community composition as well as of their nutrient and light status. As a consequence, although vertical profiles of fluorescence are likely the most recorded biological property in the open ocean, the corresponding large databases are underexploited. Here with the aim to convert a fluorescence profile into a Chl- $a$ concentration profile, we test the hypothesis that the Chl- $a$ concentration can be gathered from the sole knowledge of the shape of the fluorescence profile. We analyze a large dataset from 18 oceanographic cruises conducted in case- 1 waters from the highly stratified hyperoligotrophic waters (surface Chl- $a=0.02 \mathrm{mg} \mathrm{m}^{-3}$ ) of the South Pacific Gyre to the eutrophic waters of the Benguela upwelling (surface Chl- $a=32 \mathrm{mg} \mathrm{m}^{-3}$ ) and including the very deep mixed waters in the North Atlantic (Mixed Layer Depth $=690 \mathrm{~m}$ ). This dataset encompasses more than 700 vertical profiles of Chl- $a$ fluorescence as well as accurate estimations of Chl- $a$ by High Performance Liquid Chromatography (HPLC). Two typical fluorescence profiles are identified, the uniform profile, characterized by a homogeneous layer roughly corresponding to the mixed layer, and the non-uniform profile, characterized by the presence of a Deep Chlorophyll Maximum. Using appropriate mathematical parameterizations, a fluorescence profile is subsequently represented by 3 or 5 shape parameters for uniform or non-uniform profiles, respectively. For both situations, an empirical model is de-
\end{abstract}

Correspondence to: A. Mignot

(mignot@obs-vlfr.fr) veloped to predict the "true" Chl- $a$ concentration from these shape parameters. This model is then used to calibrate a fluorescence profile in Chl- $a$ units. The validation of the approach provides satisfactory results with a median absolute percent deviation of $33 \%$ when comparing the HPLC Chl- $a$ profiles to the Chl- $a$-calibrated fluorescence. The proposed approach thus opens the possibility to produce Chl- $a$ climatologies from uncalibrated fluorescence profile databases that have been acquired in the past and to which numerous new profiles will be added, thanks to the recent availability of autonomous platforms (profiling floats, gliders and animals) instrumented with miniature fluorometers.

\section{Introduction}

Introduced by Lorenzen in 1966, in vivo fluorescence (from now, simply referred as fluorescence) has become a widely used and popular technique to estimate Chlorophyll- $a$ (Chl- $a$ ) concentrations in aquatic environments. Subsequently, the development of in situ fluorometers that are coupled to CTD sensors has resulted in fluorescence measurements being likely the most measured biological property (together with $\mathrm{O}_{2}$ and irradiance profiles) in the open ocean. Hence, the vertical profile of Chl- $a$ concentration is measured cost-effectively and, additionally, is of fundamental help in selecting the depth levels where rosette bottles have to be closed for more in-depth analysis of biological and biogeochemical properties (including "true" Chl- $a$ concentration measurement).

Although practically simple and efficient, fluorescence measurements are nevertheless not trivial to interpret. Indeed, fluorescence measured by a fluorometer, $f$, can be basically expressed as follow:

$f=E a^{*} \phi$ Chl- $a$,

Published by Copernicus Publications on behalf of the European Geosciences Union. 
where $E$ is the intensity of the excitation source (mole quanta $\left.\mathrm{m}^{-2} \mathrm{~s}^{-1}\right), a^{*}$ is the specific absorption coefficient $\left(\mathrm{m}^{2} \mathrm{mg} \mathrm{Chl}-a^{-1}\right)$, Chl- $a$ is the Chlorophyll- $a$ concentration (mg Chl- $a \mathrm{~m}^{-3}$ ) and $\phi$ is the fluorescence quantum yield (mole quanta emitted mole quanta absorbed ${ }^{-1}$ ). From Eq. (1), it comes that $f$ has units of mole quanta $\mathrm{m}^{-3} \mathrm{~s}^{-1}$ and that various instruments (with different light source intensities, detectors, volumes of detection) will give different fluorescence values for the same Chl- $a$. Calibration of the fluorescence measurements against true Chl- $a$ measurement is thus mandatory. This remark is critical because many fluorescence profiles have been acquired or are still acquired without any concurrent Chl- $a$ determination. In general, sensors are factory-calibrated, regressing instrument response to pure Chl- $a$ or to phytoplankton cultures of various concentrations. However, these simple calibrations do not necessarily correspond to the range of the actual in situ Chl- $a$ concentration as well as to diversity of phytoplankton communities where fluorometers are operated. Furthermore, the instruments drift over time and re-calibration is not always possible or done. Consequently, fluorescence measurements are very frequently reported in terms of relative units. As a consequence the large fluorescence database (e.g. $\sim 49000$ on National Oceanographic Data Center NODC; http://www. nodc.noaa.gov/) which consists of the pooling of vertical profiles from various cruises and sensors are not sufficiently consistent for developing more comprehensive studies, like the development of Chl- $a$ climatologies for the global ocean (e.g. Gregg and Conkright, 2002).

Thanks to the miniaturization of bio-optical sensors, autonomous platforms (floats, gliders, animals) are now capable of acquiring vertical profiles of fluorescence over large distances (Sackmann et al., 2008; Niewiadomska et al., 2008, Claustre et al., 2010a) or periods (up to $3 \mathrm{yr}$ ) (Boss et al., 2008). The extension and generalization of these "biogeochemical platforms" as part of a global network (Claustre et al., 2010a, b) similar to the Argo network (Roemmich et al., 2010; Freeland et al., 2010) is expected for the near future. The 3000 floats of the Argo program are now operationally acquiring $\sim 120000$ temperature and salinity profiles per annum, i.e. $\sim 95 \%$ of the total profiles acquired yearly. Similarly, in the coming years a tremendous increase in the number of fluorescence profiles acquired in the global ocean can be expected. The issues related to calibration and to the significance of the Chl- $a$ fluorescence signal will become even more critical for these platforms especially for floats and animals for which sensors cannot be recovered for "post-cruise" re-calibration. Alternative strategies and methods are thus required for these fluorescence measurements and to ensure the consistency of the future (very large) data-base (e.g. Xing et al., 2011; Boss et al., 2008).
Several clues indicate that a relationship exists between the Chl- $a$ concentration and the shape of its vertical distribution. In stratified waters, for example, characterized by a Deep Chlorophyll Maximum (DCM), surface Chl- $a$ increases when the DCM progressively rises towards the surface. The extreme situation can be observed for the hyper oligotrophic waters of the South Pacific Gyre during the austral summer where surface Chl- $a$ is the lowest $\left(\sim 0.02 \mathrm{mg} \mathrm{Chl}-a \mathrm{~m}^{-3}\right)$ and the DCM is the deepest (Ras et al., 2008) among the world's oceans. The potential link between surface Chl- $a$ and the depth of the DCM in stratified environments was highlighted by Morel and Berthon (1989) and Uitz et al. (2006). Both studies subsequently proposed a parameterization of the vertical distribution of Chl- $a$ from the sole knowledge of the surface, potentially remotelydetected, Chl- $a$ concentration.

Similar observations between shape and concentration also exist for mixed waters. In these, the vertical structure of Chl- $a$ is homogeneous in the mixed layer. Chl- $a$ increases when the depth of the mixed layer decreases (Ward and Waniek, 2007). Again a link is expected between the thickness and the Chl- $a$ concentration of the layer.

The present study is in line with the above observations. It is initiated by the need for new procedures for deriving Chl- $a$ vertical distribution from fluorescence profiles, even if these profiles have not been properly (or not at all) calibrated. Since we expect a potential relationship between the shape of the profile and the Chl- $a$ concentration, we analyze here a global ocean database of fluorescence profiles simultaneously acquired with accurate Chl- $a$ determination through HPLC (High Pressure Liquid Chromatography). We first propose mathematical expressions describing the various shapes of fluorescence vertical profiles that can be observed in natural waters. We then establish empirical relationships between depth-dependent shape parameters derived from these expressions and HPLC Chl- $a$. We finally propose a method for the "recalibration" of a fluorescence profile in terms of Chl- $a$, from the sole knowledge of the profile shape.

\section{Background}

\subsection{Variable definition and calculation}

The different variables used in this study and their associated symbols, definitions and units are detailed in Table 1. Here, only a description of the calculation of the euphotic depth, the first penetration depth and the mixed layer depth is given.

The depth of the euphotic layer, $Z_{\mathrm{e}}(\mathrm{m})$, defined as the depth where irradiance is reduced to $1 \%$ of its surface value, is estimated according to Morel and Berthon (1989) using the Chl- $a$ vertical profiles. The statistical relationships presented by Morel and Berthon (1989) and linking $Z_{\mathrm{e}}$ to the integrated content in Chl- $a$, is here updated using the parameterization proposed by Morel and Maritorena (2001). 
Table 1. Symbols used in this study.

\begin{tabular}{|c|c|c|}
\hline Symbol & Definition & Units \\
\hline$z$ & Depth & $\mathrm{m}$ \\
\hline$Z_{\mathrm{e}}$ & Depth of the euphotic layer & $\mathrm{m}$ \\
\hline$Z_{\mathrm{pd}}$ & First penetration depth & $\mathrm{m}$ \\
\hline$Z_{\mathrm{m}}$ & Mixed layer Depth & $\mathrm{m}$ \\
\hline$\sigma_{\theta}$ & Potential density anomaly & $\mathrm{kg} \mathrm{m}^{-3}$ \\
\hline Chl- $a$ & HPLC Chlorophyll- $a$ concentration & $\mathrm{mg} \mathrm{m}^{-3}$ \\
\hline $\mathrm{Chl}_{\text {surf }}$ & $\begin{array}{l}\text { Arithmetic average HPLC Chl- } a \text { concentration in the first penetration } \\
\text { depth }\end{array}$ & $\mathrm{mg} \mathrm{m}^{-3}$ \\
\hline $\mathrm{Chl}_{\max }$ & Maximum HPLC Chl- $a$ concentration & $\mathrm{mg} \mathrm{m}^{-3}$ \\
\hline$\left[\mathrm{Chl}_{\mathrm{ze}}\right]$ & HPLC Chl- $a$ column-integrated content within the euphotic layer & $\mathrm{mg} \mathrm{m}^{-2}$ \\
\hline$\left[\mathrm{Chl}_{Z 1 / 2}\right]$ & HPLC Chl- $a$ column-integrated content within $Z_{1 / 2}$ & $\mathrm{mg} \mathrm{m}^{-2}$ \\
\hline$f(z)$ & Fluorescence profile & relative units \\
\hline$F(z)$ & Fluorescence fit & relative units \\
\hline$F_{\text {surf }}$ & $\begin{array}{l}\text { Fluorescence value at } z=0 \text { of the exponential decrease and the sig- } \\
\text { moid fit }\end{array}$ & relative units \\
\hline$F_{\max }$ & Maximum value of the Gaussian fit & relative units \\
\hline$Z_{1 / 2}$ & Depth where $F_{\text {surf }}$ is divided by 2 & $\mathrm{~m}$ \\
\hline$Z_{\max }$ & Depth of the Gaussian fit maximum & $\mathrm{m}$ \\
\hline$d z$ & Proxy of the Gaussian fit thickness & $\mathrm{m}$ \\
\hline$s$ & Proxy of the sigmoid fit slope at $Z_{1 / 2}$ & $\mathrm{~m}^{-1}$ \\
\hline$f_{0}(z)$ & Fluorescence profile set to 0 at bottom & relative units \\
\hline$F_{\text {surf }}^{c}$ & $F_{\text {surf }}$ calibrated in units of Chl- $a$ & $\mathrm{mg} \mathrm{m}^{-3}$ \\
\hline$F_{\max }^{c}$ & $F_{\max }$ calibrated in units of Chl- $a$ & $\mathrm{mg} \mathrm{m}^{-3}$ \\
\hline$F^{c}(z)$ & $F(z)$ calibrated in units of Chl- $a$ & $\mathrm{mg} \mathrm{m}^{-3}$ \\
\hline$\varepsilon(z)$ & Fluorescence fit residuals: $f_{0}(z)-F(z)$ & relative units \\
\hline$\varepsilon^{c}(z)$ & $\varepsilon(z)$ calibrated in units of Chl- $a$ & $\mathrm{mg} \mathrm{m}^{-3}$ \\
\hline$f^{c}(z)$ & $f(z)$ calibrated in units of Chl- $a$ & $\mathrm{mg} \mathrm{m}^{-3}$ \\
\hline
\end{tabular}

The first penetration depth, $Z_{\mathrm{pd}}(\mathrm{m})$, is defined as $Z_{\mathrm{e}} / 4.6$. Note that this quantity is also used for ocean color remote sensing studies, where it delineates the surface layer actually "seen" by the satellite.

The mixed layer depth $Z_{\mathrm{m}}(\mathrm{m})$ is calculated as the depth where the density value is $0.03 \mathrm{~kg} \mathrm{~m}^{-3}$ in excess with respect to the value at $10 \mathrm{~m}$ (de Boyer-Montegut et al., 2004).

\subsection{Parameterization of the fluorescence vertical profile}

In the present study, we assume as in Morel and Berthon (1989) and Uitz et al. (2006) that in the open ocean, the vertical distribution of Chl- $a$, or equivalently of fluorescence, can be divided into two main types, uniform and non-uniform. The two categories were initially defined with respect to the $Z_{\mathrm{e}} / Z_{\mathrm{m}}$ ratio. For example, in the South $\mathrm{Pa}$ cific Gyre during the austral summer (Fig. 1a), $Z_{\mathrm{e}}(160 \mathrm{~m})$ is greater than $Z_{\mathrm{m}}(55 \mathrm{~m})$. The vertical distribution of fluorescence is non-uniform and shows a well-pronounced DCM. This vertical fluorescence profile is typical of stratified water $\left(Z_{\mathrm{e}} / Z_{\mathrm{m}}>1\right)$. Conversely, in the North Atlantic during the boreal winter (Fig. 1b), $Z_{\mathrm{e}}$ is $120 \mathrm{~m}$ while $Z_{\mathrm{m}}$ extends to

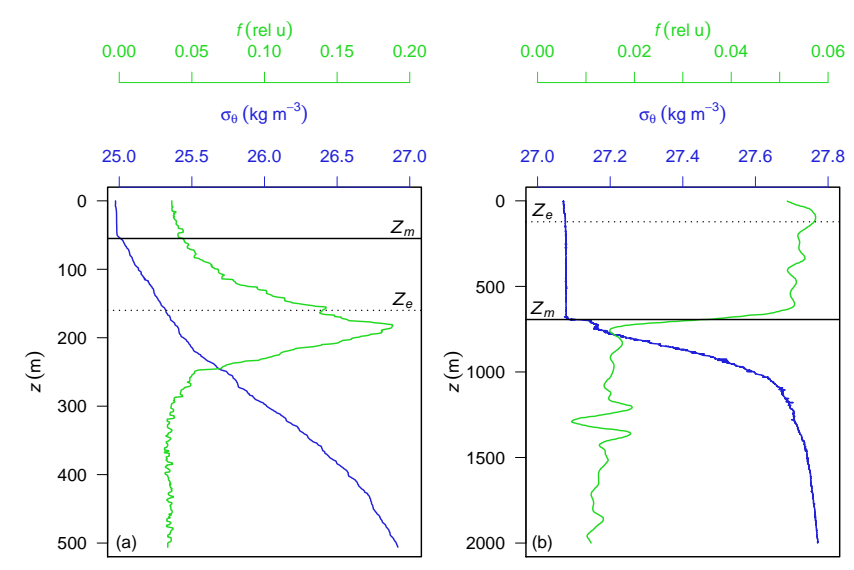

Fig. 1. Typical potential density anomaly profile $\sigma_{\theta}\left(\mathrm{kg} \mathrm{m}^{-3}\right)$ (blue line) and fluorescence profile $f$ (relative units) (green line) for (a) stratified waters and (b) mixed waters. The mixed layer depth $Z_{\mathrm{m}}$ (plain line) and the euphotic depth $Z_{\mathrm{e}}$ (dashed line) are indicated. 

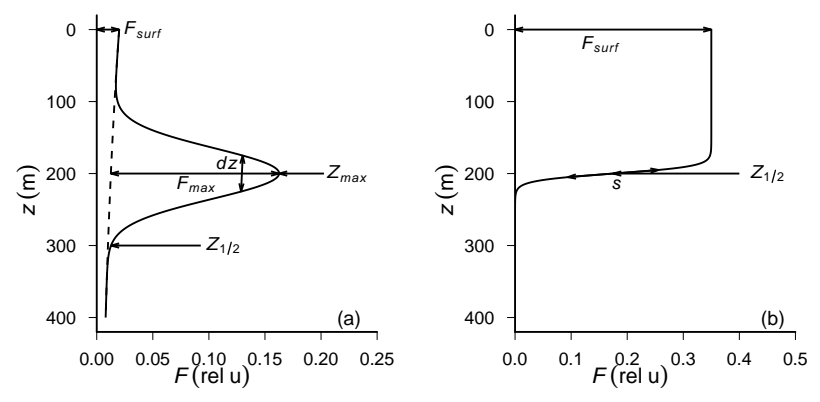

Fig. 2. Schematic representation of the vertical distribution of fluorescence with depth. (a) Case of non-uniform profile. The typical shape is modeled by a gaussian distribution (plain line) superimposed onto an exponential decrease (dashed line). The exponential decrease is defined by one concentration-dependent shape parameter $F_{\text {surf }}$ (relative units) and one depth-dependent shape parameter $Z_{1 / 2}(\mathrm{~m})$. The gaussian distribution is defined by one concentration-dependent shape parameter $F_{\max }$ and two depthdependent shape parameters $Z_{\max }(\mathrm{m})$ and $d z(\mathrm{~m})$. (b) Case of uniform profile. The typical shape is modeled by a sigmoid curve (plain line), defined by one concentration-dependent shape parameter $F_{\text {surf }}$ (relative units) and two depth-dependent shape parameters $Z_{1 / 2}(\mathrm{~m})$ and $s\left(\mathrm{~m}^{-1}\right)$. See Table 1 for definitions.

$\sim 700 \mathrm{~m}$. The vertical distribution of fluorescence is uniform until $Z_{\mathrm{m}}$ and then decreases with depth to a null fluorescence. This vertical profile is typical of mixed waters $\left(Z_{\mathrm{e}} / Z_{\mathrm{m}}<1\right)$.

The non-uniform vertical Chl- $a$ profile was first modeled by Lewis et al. (1983) with a generalized gaussian, which has subsequently been widely used with small modifications. In particular, to account for the observed characteristic that surface values always exceed the bottom ones, gaussian functional form has been modified with a superimposition of a background either constant (Platt et al., 1988; Morel and Berthon, 1989; Hidalgo-Gonzalez and Alvarez-Borrego, 2001; Richardson et al., 2003) or linearly decreasing with depth (Uitz et al., 2006). Here, we propose a slightly improved parameterization by modeling the background using an exponential decrease with depth. This exponential decrease is implemented to better reproduce the Chl- $a$ decrease from the surface towards the bottom where Chl- $a$ concentration converges to a null value. The proposed new parameterization of the vertical profile of fluorescence is thus as follows (Fig. 2a):

$F(z)=F_{\text {surf }} e^{\frac{-\ln 2}{Z_{1 / 2}} z}+F_{\max } e^{\frac{-\left(z-Z_{\max }\right)^{2}}{d z^{2}}}$.

The exponential decrease background is characterized by its value at the surface $F_{\text {surf }}$ (relative units) and the depth where this value is divided by $2, Z_{1 / 2}(\mathrm{~m})$. A gaussian curve is superimposed onto it with a maximum value $F_{\max }$ (relative units) occurring at $Z_{\max }(\mathrm{m})$ and having a thickness controlled by $d z(\mathrm{~m})$.
The uniform vertical Chl- $a$ profile is usually parameterized with a uniform value up to $Z_{\mathrm{e}}$ (Uitz et al., 2006). This is not relevant here because, for such profiles, Chl- $a$ is expected to be homogenous within $0-Z_{\mathrm{m}}$, and to decrease towards zero below $Z_{\mathrm{m}}$. The sigmoid curve, which allows capturing this property, is adopted here (Fig. 2b):

$F(z)=F_{\text {surf }} \frac{1}{1+e^{\left(Z_{1 / 2}-z\right) s}}$.

$F_{\text {surf }}$ (relative units) corresponds to the asymptote of the function at the surface, $Z_{1 / 2}(\mathrm{~m})$ is the inflection point and $s\left(\mathrm{~m}^{-1}\right)$ the strength of the inflection.

The descriptors of the fluorescence profile which refer to a depth $\left(Z_{\max }, d z, Z_{1 / 2}, s\right)$ will be hereafter named as depth-dependent shape parameters. Similarly, those referring to a fluorescence value ( $\left.F_{\text {surf }}, F_{\max }\right)$ will be named as concentration-dependent shape parameters.

\section{Materials and methods}

\subsection{Dataset and quality control}

Data used in this study were collected as part of 18 open ocean cruises in the period 1991-2008 (Table 2). For each sampling site, the required data are fluorescence profiles associated with simultaneous determination of Chl- $a$ through HPLC at discrete depths.

All fluorescence and HPLC data used were properly validated. Additionally, some of the HPLC data (PROSOPE, BENCAL and BIOSOPE cruise) were acquired as part of NASA-driven HPLC intercomparison exercises (Claustre et al., 2004; Hooker et al., 2005, 2009). An additional quality control procedure on fluorescence and HPLC has been also carried out, to increase homogeneity of the whole dataset. The quality assurance described in Uitz et al. (2006) is applied to each Chl- $a$ profile, using the following criteria: (1) samples with Chl- $a$ lower than $0.001 \mathrm{mg} \mathrm{m}^{-3}$ are rejected then the following criteria must be met: (2) the first sampling depth has to be above $10 \mathrm{~m}$; (3) the last sampling depth has to be greater or equal than $Z_{\mathrm{e}}$; (4) a minimum of four sampling depths is required for each profile. For fluorescence profiles, aberrant data due to electronic noise are removed using a dedicated quality control procedure described in D'Ortenzio et al. (2010). To account that the deep fluorescence values are still non-null in the absence of algal fluorescence, the fluorescence profile is set to 0 at the bottom by substracting the mean of the 10 deepest points from the profile. The profile has also to satisfy the additional condition that its maximal depth is deep enough to allow the shape parameter $Z_{1 / 2}$ to be retrieved; if not, the profile is rejected. 
Table 2. Abbreviation, location, sampling period and number of stations (after quality control) for the different cruises/projects used in the dataset.

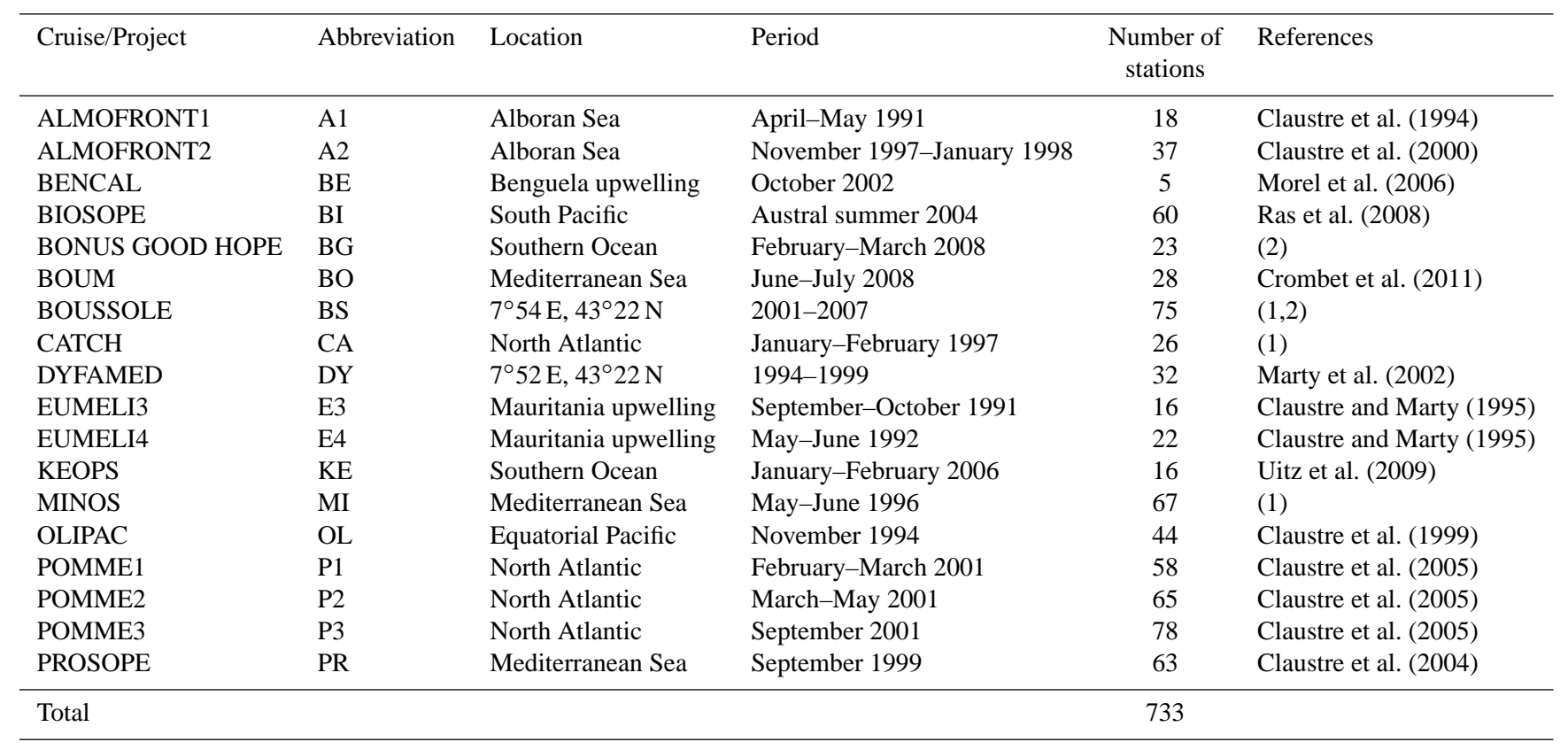

(1) Chl- $a$ was analysed according to Vidussi et al. (1996).

(2) Chl- $a$ was analysed according to Ras et al. (2008).
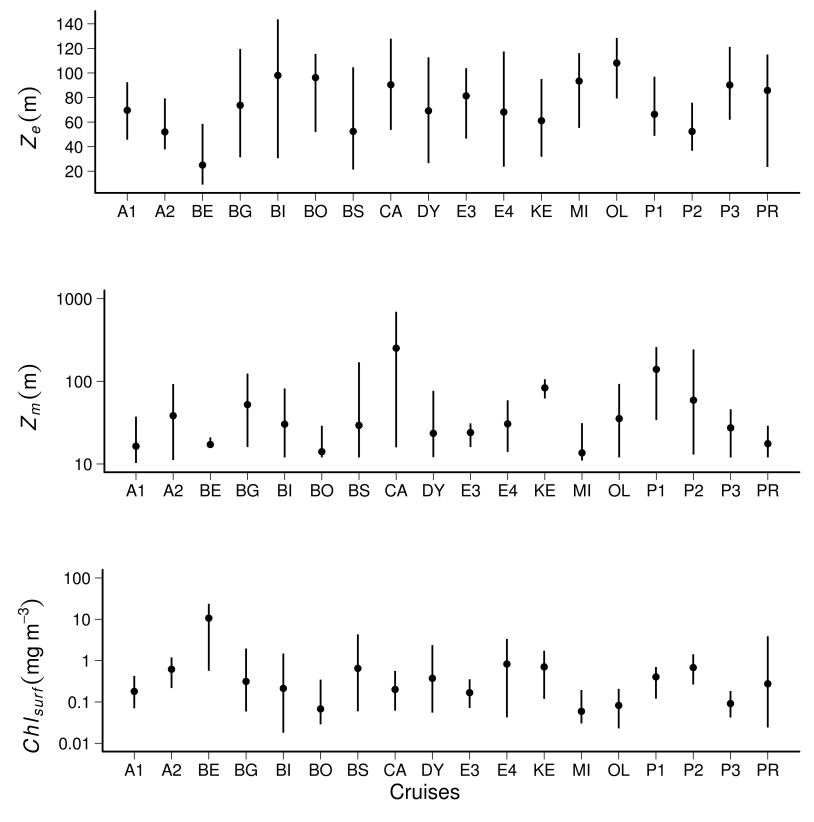

Fig. 3. General characteristics of the dataset used in this study. Range (line) and mean values (circle) of $Z_{\mathrm{e}}(\mathrm{m}), Z_{\mathrm{m}}(\mathrm{m})$ and $\mathrm{Chl}$ surf $\left(\mathrm{mg} \mathrm{m}^{-3}\right)$ for the 18 Cruises. See Table 2 for abbreviations of the different cruises/projects.

\subsection{Dataset characteristics}

The dataset covers a large range of optical, hydrological and associated trophic conditions (Fig. 3). The hydrological conditions range from deep mixed waters $\left(Z_{\mathrm{m}} \sim 700 \mathrm{~m} ; \mathrm{CATCH}\right.$ cruise in the North Atlantic during winter), to extremely stratified waters (center of South Pacific Gyre; BIOSOPE cruise, in spring). $\mathrm{Chl}_{\text {surf }}$ covers three orders of magnitude, from hyperoligotrophic conditions $\left(0.02 \mathrm{mg} \mathrm{m}^{-3}\right.$; BIOSOPE cruise) to the eutrophic conditions of the Benguela upwelling (32 $\mathrm{mg} \mathrm{m}^{-3}$; BENCAL cruise). The dataset thus is largely representative of the diverse conditions naturally observed in the open ocean. It is therefore expected that the parameterization and the conclusions resulting from this dataset analysis will be of general applicability, especially with respect to the potential link between fluorescence shape and Chl- $a$.

\subsection{Sorting the data}

Establishing relationships between the shape of the fluorescence and Chl- $a$ concentration is initially required to define a gaussian or sigmoid shape for a given profile. It is usually based on the ratio between $Z_{\mathrm{m}}$ and $Z_{\mathrm{e}}$, which classifies a profile according to prevailing conditions (Uitz et al., 2006). Nevertheless, the goal of the present study is eventually to calibrate a vertical fluorescence profile from the sole knowledge of its shape, without any additional data. This is, for example, required for database where the fluorescence profile 
is not systematically associated with a CTD one (for $Z_{\mathrm{m}}$ determination) and even more frequently where $Z_{\mathrm{e}}$ is not available or derivable (from Chl- $a$ profile for example or from radiometric measurements). Therefore, alternative procedures of profile classification have to be developed.

Each profile of the dataset was fitted with both the gaussian Eq. (2) and sigmoid Eq. (3) parameterizations using a quasiNewton least square algorithm ( $\mathrm{R}$ development Core Team, 2010). The shape explaining the best the profile variance is considered as the representative one only if the square of the coefficient of determination $r^{2}$ is greater than 0.8 . If not, the profile is flagged as "other". Fitting classified $62.6 \%, 31.8 \%$ and $5.6 \%$ of profiles as "gaussian", "sigmoid" or "others", respectively. The "others" class was limited to some specific cruises (ALMOFRONT, Table 1) where double fluorescence and Chl- $a$ peaks were recorded (Claustre et al., 1994). In such anomalous cases, the proposed parameterizations do not fit the observed data, and other shape models should be introduced. However, "anomalous" profiles are rarely observed in open ocean, as confirmed by our dataset, (i.e. less than $6 \%$ of profiles classified in "others"), and we decided to maintain only two model shapes for the rest of our analysis.

\subsection{Statistical indicators}

We use 6 statistical indicators to evaluate the performance of the validation of the method.

The first three indicators are relative to the least square regression fitted within the $\log _{10}$-transformed data (to account for Chl- $a$ ranging over three orders of magnitude and being lognormally distributed; Campbell, 1995): the coefficient of determination $r^{2}$, slope and intercept. We also computed the Root Mean Square Error (RMSE) between the Chl- $a$ calibrated fluorescence $f^{c}$ (see later Table 1) and Chl- $a$, which indicates the scatter of the data,

RMSE $=\sqrt{\frac{1}{n} \sum_{i=1}^{n}\left(\log _{10}\left(f^{c}\right)-\log _{10}(\text { Chl- } a)\right)^{2}}$,

where $n$ is the number of points.

The Relative Percent Deviation (RPD), which gives information about the over or underestimation of $f^{c}$ compared to Chl- $a$ was calculated as following:

$\mathrm{RPD}=\frac{f^{c}-\mathrm{Chl}-a}{\mathrm{Chl}-a} \times 100$.

Finally, the uncertainty of the method was calculated through the Absolute Percent Deviation (APD):

$\mathrm{APD}=\frac{\left|f^{c}-\mathrm{Chl}-a\right|}{\text { Chl }-a} \times 100$.

We then calculate the median of the RPD and the APD (instead the average) in order to minimize the effect of extreme values.

\section{Results and discussion}

\subsection{Gaussian profiles: relationship between the depth-dependent shape parameters and Chl- $a$}

For gaussian profiles (456 profiles), the relationships among the three depth-dependent shape parameters $\left(Z_{\max }, Z_{1 / 2}, d z\right)$ and $\mathrm{Chl}_{\text {surf }}, \mathrm{Chl}_{\max },\left[\mathrm{Chl}_{\mathrm{ze}}\right]$ and $Z_{\mathrm{e}}$ are presented in Fig. 4.

The most oligotrophic conditions $\left(\mathrm{Chl}_{\text {surf }}=0.02 \mathrm{mg} \mathrm{m}^{-3}\right.$, $\left.\mathrm{Chl}_{\max }=0.12 \mathrm{mg} \mathrm{m}^{-3},\left[\mathrm{Chl}_{\mathrm{ze}}\right]=7.5 \mathrm{mg} \mathrm{m}^{-2}, Z_{\mathrm{e}}=145 \mathrm{~m}\right)$ are characterized by the deepest $Z_{\max }(200 \mathrm{~m})$ and $Z_{1 / 2}$ $(340 \mathrm{~m})$ as well as the broadest $d z(75 \mathrm{~m})$. As expected, increase in $\mathrm{Chl}_{\text {surf }}, \mathrm{Chl}_{\max }$, [Chl $\left.\mathrm{Ce}_{\mathrm{ze}}\right]$ correspond to a decrease in $Z_{\mathrm{e}}$ and result in a shallow $Z_{1 / 2}, Z_{\max }$ and a narrow $d z$.

Eutrophic conditions $\left(\mathrm{Chl}_{\text {surf }}\right.$ and $\mathrm{Chl}_{\max }$ in the $1-3 \mathrm{mg} \mathrm{m}^{-3}$ range; [Chl $\mathrm{Ce}_{\text {e }}$ between 50 and $70 \mathrm{mg} \mathrm{m}^{-2} ; Z_{\mathrm{e}}$ at $\sim 20 \mathrm{~m}$ ), are characterized by $Z_{\max }$ and $Z_{1 / 2}$ close to the surface (15-20 and 35-50 m, respectively), and by an extremely narrow $d z$ (e.g. $4 \mathrm{~m}$ for some profiles).

To quantify the links between the depth-dependent shape parameters $\left(Z_{\max }, Z_{1 / 2}, d z\right)$ and $\mathrm{Chl}_{\text {surf }}, \mathrm{Chl}_{\max }$, [Chl $\left.\mathrm{Ce}_{\mathrm{ze}}\right]$ or $Z_{\mathrm{e}}$, a polynomial fit between $\log _{10}$-transformed data was calculated for each couple of parameters (Fig. 4; order of polynomial fit in Table 3). The scatter of data around the global trends was evaluated through the coefficient of determination $\left(r^{2}\right)$ and the residual standard error (se) of the linear models (Table 3 ). The relationships $d z$ vs. $\mathrm{Chl}_{\text {surf }},\left[\mathrm{Chl}_{\mathrm{ze}}\right]$ or $Z_{\mathrm{e}}$ are the most scattered, which is not the case for the relationship between $d z$ and $\mathrm{Chl}_{\max }$. The relationships linking $Z_{1 / 2}$ to $\mathrm{Chl}_{\text {surf }}, \mathrm{Chl}_{\max }$, [Chl $\mathrm{Ce}_{\mathrm{ze}}$ or $Z_{\mathrm{e}}$ are more scattered than those linking $Z_{\max }$ to $\mathrm{Chl}_{\text {surf }}, \mathrm{Chl}_{\max }$, [Chl $\left.\mathrm{Ch}_{\mathrm{ze}}\right]$ or $Z_{\mathrm{e}} . Z_{\max }$ appears to be the most adapted variable to explain the variability in $\mathrm{Ch}_{\text {surf }}, \mathrm{Chl}_{\max }$, [Chl $\mathrm{Ce}_{\mathrm{ze}}$ or in $Z_{\mathrm{e}}$ (Fig. 4a, d, g, j). The scatter with respect to the fit is similar for $\mathrm{Ch}_{\text {surf }}$, [Chl $\left.\mathrm{Ce}_{\mathrm{ze}}\right]$ and $Z_{\mathrm{e}}\left(r^{2} \sim 0.8\right)$, whereas it is higher for $\mathrm{Chl}_{\max }\left(r^{2}=0.59\right)$.

Morel and Berthon (1989) and subsequently Uitz et al. (2006) have proposed a general formalism that, in stratified waters, accounts for the variety of DCM situations observed in open ocean waters. This formalism relies on a regular trend linking the dimensionless ratio $Z_{\max } / Z_{\mathrm{e}}$ to the dimensionless ratio $\left(\mathrm{Chl}_{\text {surf }} /\left[\mathrm{Chl}_{\mathrm{ze}}\right] / Z_{\mathrm{e}}\right)$. It holds from hyperoligotrophic to eutrophic waters, despite the likely diversity of causes for DCM establishment and maintenance over such a wide range of trophic conditions. The approach developed in the present study is totally in line with this previous formalism and its conclusions; it extrapolates it to dimension quantities $\left(Z_{\max }\right.$ versus $\mathrm{Chl}_{\text {surf }}, \mathrm{Chl}_{\max },\left[\mathrm{Chl}_{\mathrm{ze}}\right]$ and $Z_{\mathrm{e}}$ ). These relationships suggest that, in the range of variables here explored, the same processes might control the position of the DCM as well as Chl- $a$ concentration.

Phytoplankton growth requires light and nutrients. In stratified systems and especially in sub-tropical gyres, the physics is such that both requirements are generally not met simultaneously. Stratification indeed delineates two production regimes over the vertical dimension: an upper layer 

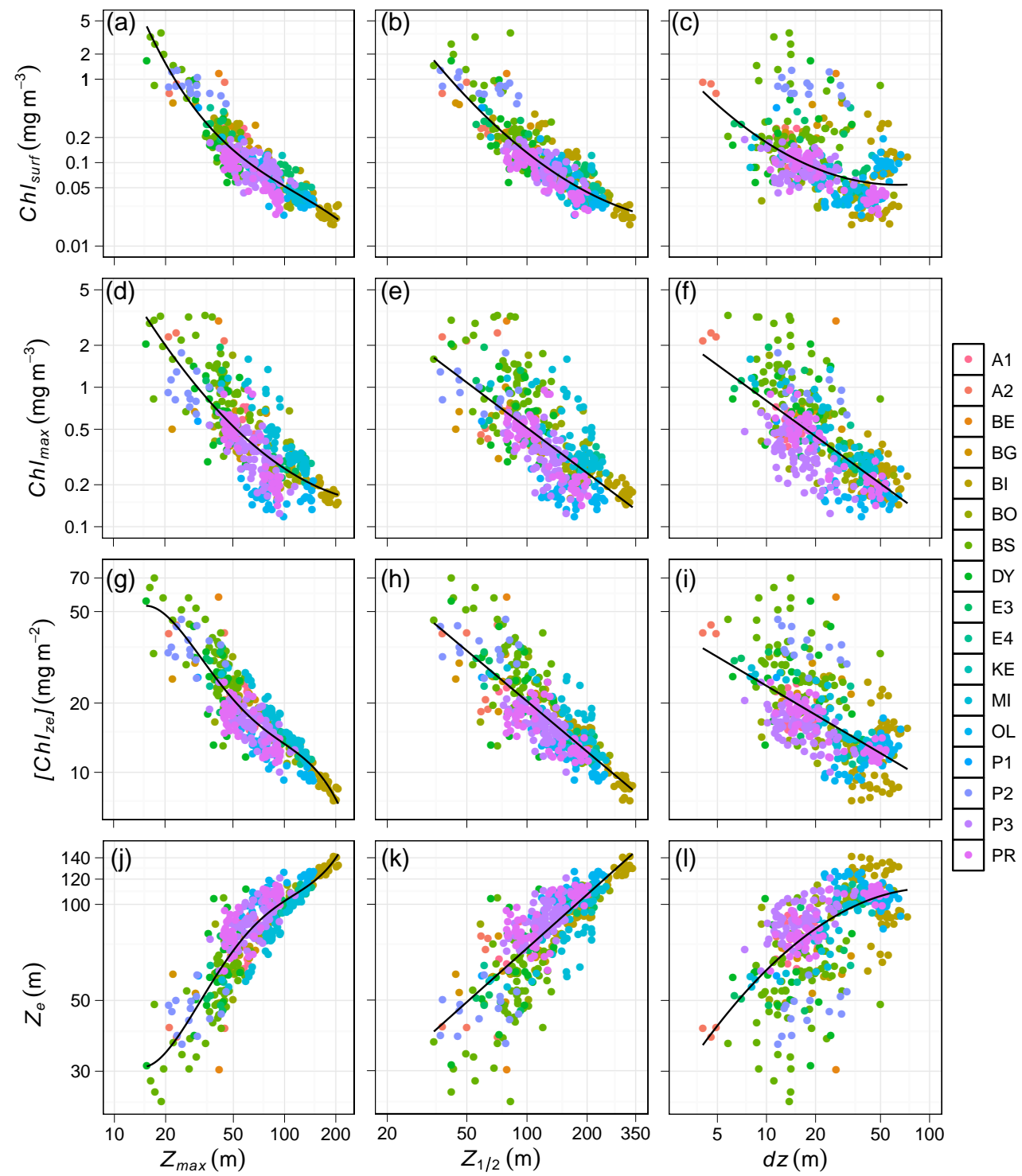

Fig. 4. Gaussian profiles: Scatterplot of $\log _{10}$-transformed $\mathrm{Chl}_{\text {surf }}\left(\mathrm{mg} \mathrm{m}^{-3}\right), \mathrm{Chl}_{\max }\left(\mathrm{mg} \mathrm{m}^{-3}\right),\left[\mathrm{Chl}_{\mathrm{ze}}\right]\left(\mathrm{mg} \mathrm{m}^{-2}\right)$ and $Z_{\mathrm{e}}$ (m) as a function of $\log _{10}$-transformed depth-dependent shape parameters $Z_{\max }(\mathrm{m}), Z_{1 / 2}(\mathrm{~m})$ and $d z(\mathrm{~m})$. Colors refer to the different cruises/projects (see Table 2 for the abbreviations). The line corresponds to the polynomial fit within the data. The order of this fit as well as the coefficient of determination and the residuals standard error are indicated in Table 3.

Table 3. Gaussian profiles: relationship between $\log _{10}$-transformed depth-dependent shape parameters and $\log _{10}$-transformed Chl- $a$ and $Z_{\mathrm{e}}$. $n, r^{2}$, se and o are the number of points, the coefficients of determination, the residuals standard error and the order of the polynomial fit, respectively.

\begin{tabular}{|c|c|c|c|c|c|c|c|c|c|c|c|c|}
\hline & \multicolumn{4}{|c|}{$Z_{\max }$} & \multicolumn{4}{|c|}{$Z_{1 / 2}$} & \multicolumn{4}{|c|}{$d z$} \\
\hline & $n$ & $r^{2}$ & se & o & $n$ & $r^{2}$ & se & o & $n$ & $r^{2}$ & se & o \\
\hline $\mathrm{Chl}_{\text {surf }}$ & 456 & 0.81 & 0.17 & 3 & 456 & 0.74 & 0.20 & 2 & 456 & 0.22 & 0.35 & 2 \\
\hline $\mathrm{Chl}_{\max }$ & 456 & 0.59 & 0.19 & 2 & 456 & 0.50 & 0.21 & 1 & 456 & 0.50 & 0.21 & 1 \\
\hline $\mathrm{Chl}_{\mathrm{ze}}$ & 456 & 0.79 & 0.08 & 4 & 456 & 0.67 & 0.10 & 1 & 456 & 0.39 & 0.14 & 1 \\
\hline$Z_{\mathrm{e}}$ & 456 & 0.78 & 0.15 & 4 & 456 & 0.65 & 0.19 & 1 & 456 & 0.38 & 0.25 & 2 \\
\hline
\end{tabular}


where phytoplankton production is nutrient-depleted and a deep layer where production is essentially light-limited. Between both layers the DCM develops. This simple conceptual view (Mann and Lazier, 1996) of stratified DCM area has been at the origin of some model development (Hodges and Rudnick, 2004).

Several studies (Herland and Voituriez, 1979; Varela et al., 1992; Estrada et al., 1993; Ediger and Yilmaz, 1996 and Mantyla et al., 2008) have demonstrated that the depth of DCM $Z_{\max }$, was tightly coupled with the upward nutrient flux (a high upward nutrient flux corresponds to a shallow DCM and reciprocally). Since the Chl- $a$ concentration, $\left(\mathrm{Chl}_{\text {surf }}\right.$ and $\left.\left[\mathrm{Chl}_{\mathrm{ze}}\right]\right)$ and $Z_{\max }$ are inversely related (Fig. $\left.4 \mathrm{a}\right)$, we state that the upward nutrient flux also controls Chl- $a$ concentration. An impoverishment in nutrients (due to reduced upward flux) in the euphotic zone leads to both a DCM deepening and a $\mathrm{Chl}_{\text {surf }}$ decrease; water becomes more transparent, and $Z_{\mathrm{e}}$ deeper while $\left[\mathrm{Chl}_{\mathrm{ze}}\right]$ decreases. Conversely, an enrichment in nutrients leads to a shallower DCM associated to higher $\mathrm{Chl}_{\text {surf }}$, shallower $Z_{\mathrm{e}}$ and larger $\left[\mathrm{Chl}_{\mathrm{ze}}\right]$.

Concerning the magnitude of the $\mathrm{DCM}, \mathrm{Chl}_{\max }$, it is controlled by both nutrient availability as well as light adaptation (Cullen, 1982; Yacobi et al., 1995). This "dual" control could be an explanation for the high scattering between $Z_{\max }$ and $\mathrm{Chl}_{\max }$ (as compared with $Z_{\max }$ and $C h l_{\text {surf }}$ ).

\subsection{Sigmoid profiles: relationship between the depth-dependent shape parameters and Chl-a}

For sigmoid profiles (234 profiles), the relationships between the depth-dependent shape parameter, $Z_{1 / 2}$ and $\mathrm{Chl}_{\text {surf }}$, $\left[\mathrm{Chl}_{\mathrm{ze}}\right]$ as well as $Z_{e}$ are presented in Fig. 5. Chl surf and [Chl $\mathrm{Ce}_{\mathrm{ze}}$ are inversely related to $Z_{1 / 2}$, while $Z_{\mathrm{e}}$ is positively related to $Z_{1 / 2}$. The deepest $Z_{1 / 2}(700 \mathrm{~m}$; CATCH cruise in the North Atlantic during winter) is associated with the lowest $\mathrm{Chl}_{\text {surf }}\left(0.05 \mathrm{mg} \mathrm{m}^{-3}\right)$, the lowest $\left[\mathrm{Chl}_{\mathrm{ze}}\right]\left(10 \mathrm{mg} \mathrm{m}^{-2}\right)$ and the deepest $Z_{\mathrm{e}}(122 \mathrm{~m})$. As $Z_{1 / 2}$ becomes shallower, $\mathrm{Chl}_{\text {surf }}$ and $\left[\mathrm{Chl}_{\mathrm{ze}}\right]$ steadily increases and $Z_{\mathrm{e}}$ becomes shallower. When $Z_{1 / 2}$ is at its shallowest $(\sim 20 \mathrm{~m}), \mathrm{Chl}_{\text {surf }}$ and $\left[\mathrm{Chl}_{\mathrm{ze}}\right]$ reach $25 \mathrm{mg} \mathrm{m}^{-3}$ and $245 \mathrm{mg} \mathrm{m}^{-2}$ respectively and $Z_{\mathrm{e}}$ is at $9 \mathrm{~m}$. This is a typical situation for upwelling waters (BENCAL cruise in the Benguela upwelling). As for stratified waters, the scatterplots of Fig. 5 can be approximated by polynomial fits between $\log _{10}$-transformed data (Table 4 ).

With a $r^{2}$ of $\sim 0.5$ between $\mathrm{Chl}_{\text {surf }},\left[\mathrm{Chl}_{\mathrm{ze}}\right]$ and $Z_{e}, Z_{1 / 2}$ appears a less efficient parameter for explaining variability in Chl- $a$ biomass in mixed waters than $Z_{\max }$ in stratified waters. Particularly, the data are significantly scattered for $\mathrm{Chl}_{\text {surf }}$ and $\left[\mathrm{Chl}_{\mathrm{ze}}\right]$ higher than $1 \mathrm{mg} \mathrm{m}^{-3}$ and $35 \mathrm{mg} \mathrm{m}^{-2}$, respectively $\left(Z_{\mathrm{e}}\right.$ lower than $\left.40 \mathrm{~m}\right)$. Note, however, that such eutrophic conditions represent only $\sim 2 \%$ of the ocean surface (Antoine et al., 1996).

In mixed waters, it is easily arguable that $Z_{1 / 2}$ is related to $Z_{\mathrm{m}}$, and even that the former could be considered as a proxy of the latter. An inverse relationship between $Z_{\mathrm{m}}$

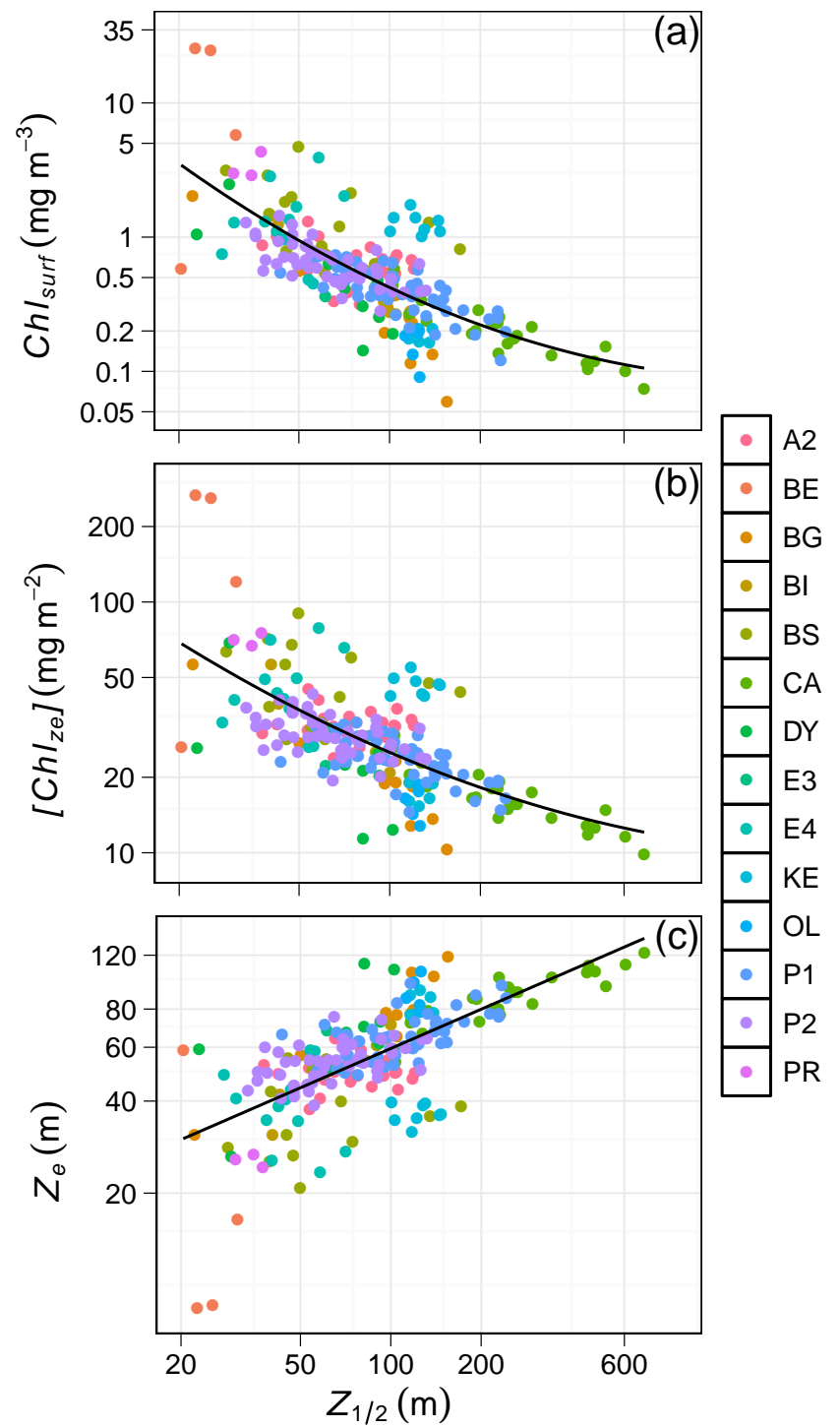

Fig. 5. Sigmoid profiles: Scatterplot of $\log _{10}$-transformed $\mathrm{Ch}_{\text {surf }}$ $\left(\mathrm{mg} \mathrm{m}^{-3}\right),\left[\mathrm{Chl}_{\mathrm{ze}}\right]\left(\mathrm{mg} \mathrm{m}^{-2}\right)$ and $Z_{\mathrm{e}}(\mathrm{m})$ as a function of $\log _{10^{-}}$ transformed depth-dependent shape parameter $Z_{1 / 2}(\mathrm{~m})$. Colors refer to the different cruises/projects (see Table 2 for the abbreviations). The line is the polynomial fit within the data. The order of this fit as well as the coefficient of determination and the residuals standard error are indicated in Table 4.

and $\mathrm{Chl}_{\text {surf }}$ has been established by observations (Ward and Waniek, 2007; Behrenfeld, 2010) and model (Steele and Menzel, 1962). But both observations and model report that the Chl- $a$ content integrated over $0-Z_{\mathrm{m}}$ is decreasing with increase in $Z_{\mathrm{m}}$. Our analysis suggests that, over a large range of mixed layer thickness, Chl- $a$ content integrated over $Z_{1 / 2}$ (more accurate to define the homogenous layer of Chl- $a$ ) $\left[\mathrm{Chl}_{Z 1 / 2}\right]$ remains relatively invariant (Fig. 6). This result means that the net production of Chl- $a$ appears not impacted by any variation in $Z_{\mathrm{m}}$. Stated differently; this implies that 
Table 4. Sigmoid profiles: relationship between $\log _{10}$-transformed depth-dependent shape parameter and $\log _{10}$-transformed Chl- $a$ and $Z_{\mathrm{e}} . n, r^{2}$, se and o are the number of points, the coefficients of determination, the residuals standard error and the order of the polynomial fit, respectively.

\begin{tabular}{l|cccc}
\hline & \multicolumn{4}{|c}{$Z_{1 / 2}$} \\
\hline & $n$ & $r^{2}$ & se & o \\
\hline Chl $_{\text {surf }}$ & 234 & 0.55 & 0.25 & 2 \\
$\mathrm{Chl}_{\text {ze }}$ & 234 & 0.47 & 0.14 & 2 \\
$Z_{\mathrm{e}}$ & 234 & 0.46 & 0.15 & 1 \\
\hline
\end{tabular}

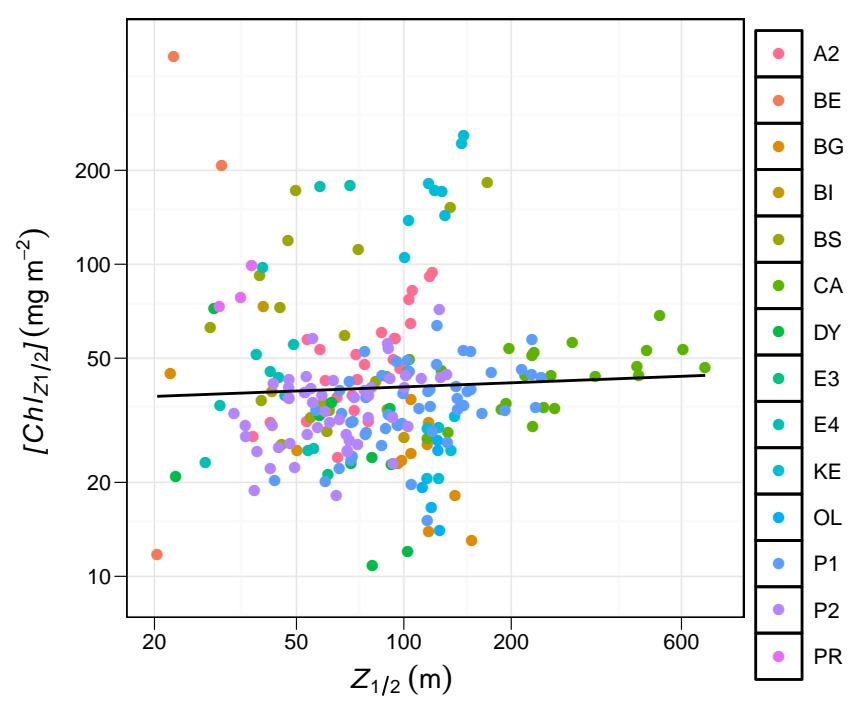

Fig. 6. Sigmoid profiles: Scatterplot of $\log _{10}$-transformed [Chl $\left.\mathrm{Cl}_{1 / 2}\right]\left(\mathrm{mg} \mathrm{m}^{-2}\right)$ as a function of $\log _{10}$-transformed depthdependent shape parameter $Z_{1 / 2}(\mathrm{~m})$. Colours refer to the different cruises/projects (see Table 2 for the abbreviations). The line is the linear regression fit within the data.

a simple dilution law could explain the observed trends reported in (Fig. 5). The deepening of $Z_{\mathrm{m}}$ dilutes the integrated Chl- $a$ concentration $\left[\mathrm{Chl}_{Z 1 / 2}\right]$ and dilutes the mean Chl- $a$ concentration in the mixed layer $\mathrm{Chl}_{\text {surf }}$ which increases the water transparency and the euphotic zone $Z_{\mathrm{e}}$ thickness, while $\left[\mathrm{Chl}_{\mathrm{ze}}\right]$ is decreasing.

\subsection{Potential impact of daytime fluorescence quenching}

Daytime-fluorescence quenching is a well-known process that affects the relationship between Chl- $a$ and fluorescence in surface waters (e.g. Cullen and Lewis, 1995; HolmHansen et al., 2000; Sackmann et al., 2008). The fluorescence signal is depressed in the upper layer of the water column, when the phytoplankton is exposed to high irradiance. Obviously this process modifies the fluorescence verti- cal structure near the surface and it can potentially affect the retrieval of a Chl- $a$ from depth-dependent shape parameters. This potential drawback is examined here.

Richardson et al. (2003) developed a procedure where fluorescence samples with high Chl- $a$ (measured fluometrically) corresponding to low fluorescence values were flagged as quenched and discarded from any subsequent statistical analysis. Following the approach of Richardson et al. (2003), we here propose a method to evaluate the "contamination" of our dataset by quenched profiles. This method is based on the relative variation of the fluorescence/Chl- $a$ ratio as a function of depth between surface and the basis of the mixed layer $Z_{\mathrm{m}}$. The fluorescence profile is considered as quenched if the slope of this regression is positive, significant $\left(r^{2}>0.50\right)$ and greater than 0.3.This analysis performed on the present dataset identifies 111 and 62 quenched profiles for gaussian (Fig. 7) and sigmoid profiles (Fig. 8), respectively. A change in fluorescence/Chl- $a$ ratio with depth could be also seen in nighttime fluorescence profiles due to spectral acclimation. However, when plotting Figs. 7 and 8 regarding day.vs.night, the slope $>0.3$ occurs predominantly during the day.

For gaussian profiles, we identified two typical situations of quenching that change the shape of the fluorescence profile (Fig. 9a, b). In the first situation (Fig. 9a), a fake DCM appears near the surface, due to the depress of fluorescence at the surface. As a consequence, a group of stations mainly representative of spring bloom conditions in temperate areas (e.g. POMME2 and some BOUSSOLE cruises) have, for the

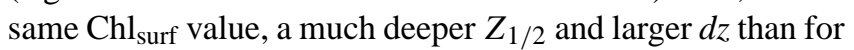
the global trend (Fig. 7b, c). At the same time $Z_{\max }$, which is very shallow, remains poorly scattered with respect to the global trend (black line on Fig. 7a). In the second situation (Fig. 9b), the fluorescence quenching enlarges the width of the DCM. The depth of the DCM remains unchanged. As a consequence, a group of stations (representative of the subequatorial and the sub-tropical South Pacific: BIOSOPE and OLIPAC cruises), reveals an overestimation of $d z$ (Fig. 7c), while $Z_{1 / 2}$ and $Z_{\max }$ remain weakly scattered with respect to the global trend (black line on Fig. 7a, b).

In summary, the influence of quenching on the vertical structure of fluorescence has a significant impact for gaussian profiles, leading to an overestimation of $Z_{1 / 2}$ and $d z$. However, $Z_{\max }$ appears much more robust with respect to quenching, confirming it as a potentially better predictor of Chl- $a$. The previous analysis, mostly based on the use of $Z_{\max }$, thus remains valid, even in conditions of day-time fluorescence quenching.

In the case of sigmoid profiles (e.g. the Equatorial Pacific in Fig. 9c), since daytime fluorescence quenching rarely affects $Z_{1 / 2}$, the quenched and non-quenched stations have similar scattering with respect to trend (Fig. 8). 

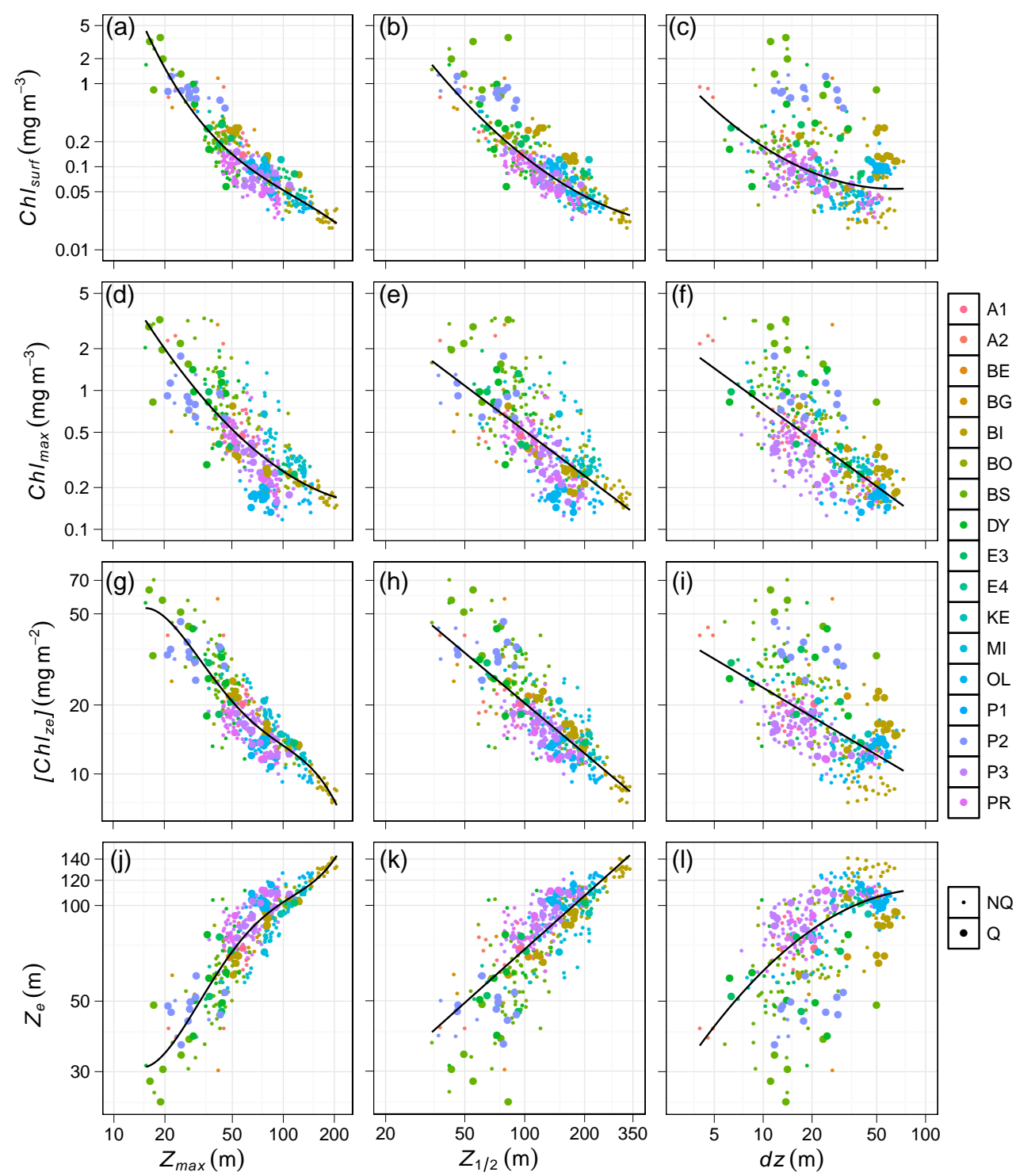

Fig. 7. Impact of quenching on the relationships presented in Fig. 4 (gaussian profiles). The quenched status of the fluorescence profile is indicated by the size of the symbol. Large circle: quenched profile. Small circle: non-quenched profile.

\subsection{From fluorescence to "true" Chl- $a$ profile}

The purpose of this section is to take the result of the previous analysis (e.g. depth-dependent shape parameters and Chl- $a$ concentration are related) to calibrate a vertical fluorescence profile (generally in relative units) in "true" units, i.e. $\mathrm{mg} \mathrm{Chl}-a \mathrm{~m}^{-3}$. According to Eqs. (2 and 3), any fluorescence profile, which is not classified as "others" (see Materials and methods), could be described by shape parameters, either depth- or concentration-dependent. Chl $\mathrm{Curf}_{\text {sund }}$ $\mathrm{Chl}_{\max }$ for gaussian profiles as well as $\mathrm{Chl}_{\text {surf }}$ for sigmoid profiles can be a priori predicted from the sole knowledge of the depth-dependent shape parameters (Figs. 4 and 5). It is further assumed that, for any vertical profile, the depth- dependent shape parameters are identical for both the uncalibrated fluorescence and the true Chl- $a$ profiles (e.g. $Z_{\max }$ is the same for fluorescence or Chl- $a$ measurements).

\subsubsection{From depth-dependent shape parameters to $\mathrm{Chl}_{\text {surf }}$ and $\mathrm{Chl}_{\max }$}

\section{Gaussian profiles}

Since $Z_{1 / 2}$ and $Z_{\max }$ are highly related $(r=0.95)$ and $d z$ is a poor predictor of $\mathrm{Chl}_{\text {surf }}$ (Fig. 4 and Table 3), $\mathrm{Chl}_{\text {surf }}$ is only predicted from $Z_{\max }$, through: 


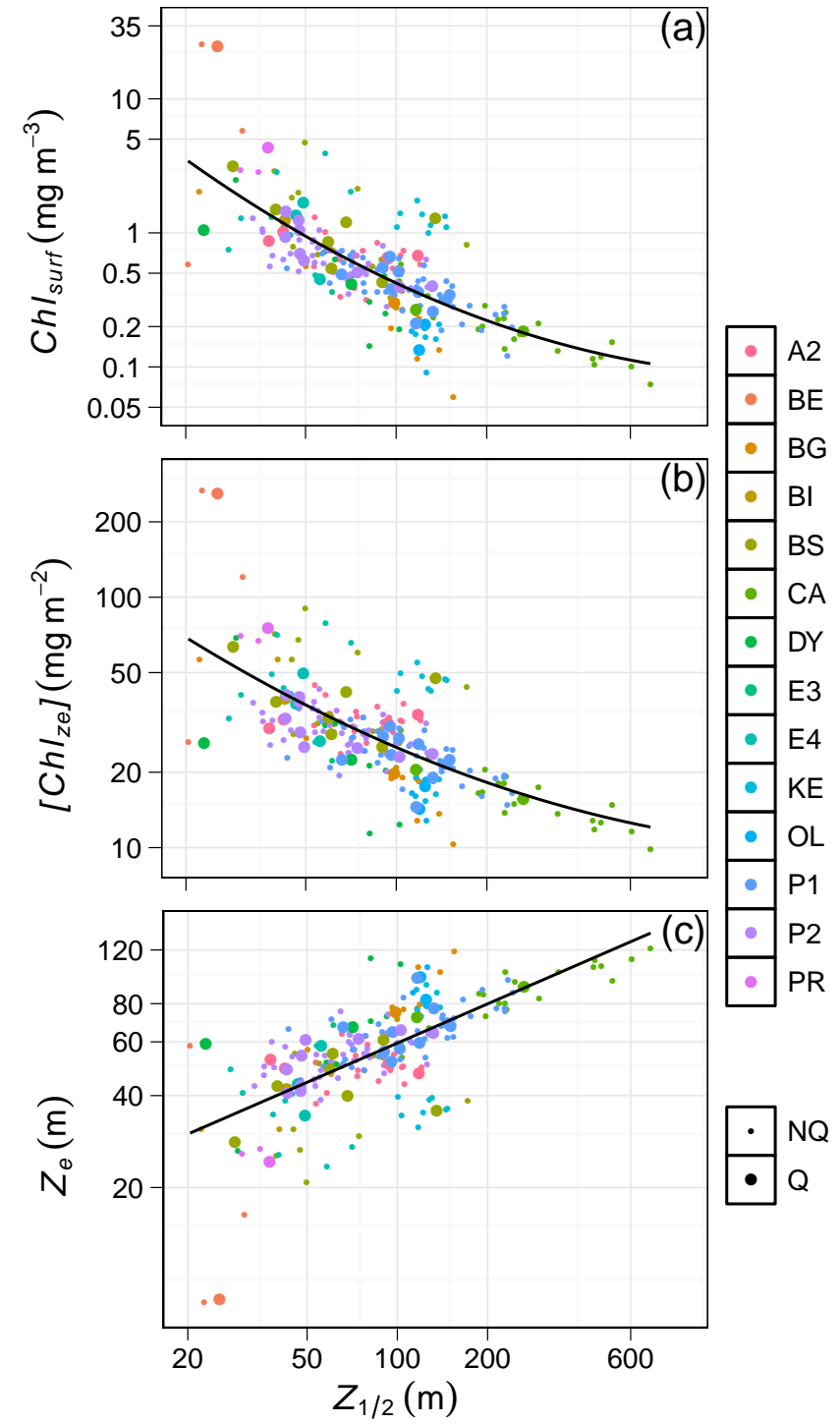

Fig. 8. Impact of quenching on the relationships presented in Fig. 5 (sigmoid profiles). The quenched status of the fluorescence profile is indicated by the size of the symbol. Large circle: quenched profile. Small circle: non-quenched profile.

$\log _{10}\left(\mathrm{Chl}_{\text {surf }}\right)=12.1335-16.8858 \log _{10}\left(Z_{\max }\right)$

$+7.4316 \log _{10}\left(Z_{\max }\right)^{2}-1.1726 \log _{10}\left(Z_{\max }\right)^{3}$,

$\left(n=456, r^{2}=0.81\right.$, se $\left.=0.17\right)$.

Since $\mathrm{Chl}_{\max }$ variability is explained in a similar way by $Z_{\text {max }}$ and $d z$ (Fig. 4 and Table 3), $\mathrm{Chl}_{\max }$ is predicted from a combination of both shape parameters according to:

$\log _{10}\left(\mathrm{Chl}_{\max }\right)=4.19161-3.59936 \log _{10}\left(Z_{\max }\right)$

$+0.79558 \log _{10}\left(Z_{\max }\right)^{2}-0.50863 \log _{10}(d z)$,

$\left(n=456, r^{2}=0.69\right.$, se $\left.=0.16\right)$.

\section{Sigmoid Profiles}

$\mathrm{Chl}_{\text {surf }}$ is directly predicted from $Z_{1 / 2}$

$\log _{10}\left(\mathrm{Chl}_{\text {surf }}\right)=3.2240-2.5795 \log _{10}\left(Z_{1 / 2}\right)$

$+0.3868 \log _{10}\left(Z_{1 / 2}\right)^{2}$,

$\left(n=234, r^{2}=0.55\right.$, se $\left.=0.25\right)$.

\subsubsection{The various steps of a fluorescence profile calibration into a Chl- $a$ profile}

The sequence for calibrating a fluorescence profile into a vertical profile of Chl- $a$ is as follows, for both gaussian (Fig. 10a) and sigmoid profiles (Fig. 10b):

1. Step 1: $f(z)$ (the raw fluorescence profile) is set to 0 at the bottom by subtracting the mean of the 10 deepest points from the profile. This step corresponds to the removal of a background fluorescence at depth to conform with expected null Chl- $a$ at a certain depth. The resulting profile is now called $f_{0}(z)$.

2. Step 2: $f_{0}(z)$ is fitted by the appropriate parameterization (Eqs. 2 and 3) in order to extract the shape parameters. From these shape parameters, a fluorescence profile can be modeled. It is named $F(z)$ and is still in relative units (blue curve).

3. Step 3: $\mathrm{Chl}_{\text {surf }}$ and $\mathrm{Chl}_{\max }$ (for gaussian profiles) are derived from depth-dependent shape parameters through empirical relationships already presented (Eqs. 7 and 9) so that Chl- $a$-calibrated concentration-dependent shape parameters $\left(F_{\text {surf }}^{c}\right.$ and $F_{\text {max }}^{c}$ ) can now be estimated from:

$F_{\text {surf }}^{c}+F_{\max }^{c} e^{\frac{Z_{\max }^{2}}{d z^{2}}}=\mathrm{Chl}_{\text {surf }}$,

$F_{\text {surf }}^{c} e^{\frac{-\ln 2}{Z_{1 / 2}} Z_{\max }}+F_{\max }^{c}=\mathrm{Chl}_{\max }$.

For sigmoid profiles, the new condition is:

$F_{\text {surf }}^{c}=\mathrm{Chl}_{\text {surf }}$.

$F^{c}(z)$ (green curve) now corresponds to the modeled Chl- $a$-calibrated fluorescence profile, now expressed in $\mathrm{mg}$ Chl- $a \mathrm{~m}^{-3}$.

4. Step 4: $\varepsilon(z)$ is defined as the vertical profile of the difference between the actual $f_{0}(z)$ and the modeled $F(z)$ fluorescence profile. It is expressed in relative units. It is further calibrated in Chl- $a$ units by multiplying it by the slope of the linear regression between $F^{c}(z)$ and $F(z)$, to obtain $\varepsilon^{c}(z)$ (note that this calibration of $\varepsilon(z)$ takes an average water column value for the ratio $F$ to $\left.F^{c}\right)$. Adding $\varepsilon^{c}(z)$ to $F^{c}(z)$ allows restoring the initial vertical fluorescence profile (black line) into a vertical Chl- $a$-calibrated fluorescence profile which is named $f^{c}(z)$ (purple line). 

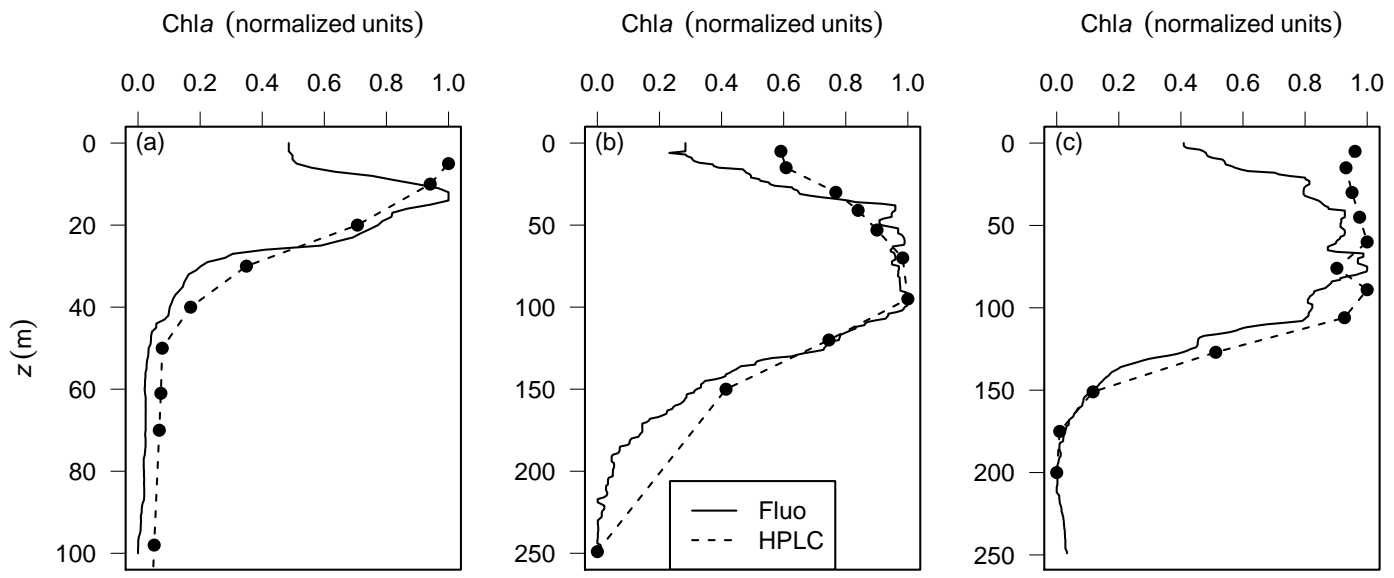

Fig. 9. Fluorescence profile (plain line) and HPLC Chl- $a$ profile (dashed line, black dots) in three typical situations of quenching. The fluorescence and Chl- $a$ units are normalized (between 0 and 1). (a) POMME2 cruise at $7.898^{\circ} \mathrm{W}, 43.369^{\circ} \mathrm{N}$ on the 11 of April 2001 . (b) BIOSOPE cruise at $86.78^{\circ} \mathrm{W}, 32.40^{\circ} \mathrm{S}$ on the 1 December 2004. (c) OLIPAC cruise at $149.99^{\circ} \mathrm{E}, 1^{\circ} \mathrm{N}$ on the $15 \mathrm{November} 1994$.

\subsection{Method validation}

The validation process is performed by a 10 -fold cross validation. The original dataset comprising the Chl- $a$ measurements together with contemporaneous and co-located fluorescence profiles is randomly partitioned into 10 subsets. Among these subsets, one is retained as the validation dataset, while the 9 remaining subsets were used to build the predictive relationships between the depth-dependent shape parameters and Chl- $a$ concentrations (same type of equation as Eqs. 7 and 9). This cross-validation process is successively repeated 10 times, with each of the 10 subsets being used only once as a validation dataset.

In every validation dataset, each fluorescence profile is calibrated using the method described in Sect. 4.4.2. The resulting Chl- $a$-calibrated fluorescence is compared with HPLC Chl- $a$ at the depth of HPLC samples. Only samples at depths within the euphotic zone were retained (below $Z_{\mathrm{e}}$, very low Chl $-a$ values could bias the analysis). The validation is then performed on 3770 samples, divided into 2786 gaussian sample and 984 sigmoid samples.

Overall, the retrieval of true Chl- $a$ from the sole knowledge of the fluorescence profile shape appears highly satisfactory given the large range of Chl- $a$ explored in this study (Fig. 11). Chl- $a$-calibrated fluorescence indeed agree with HPLC Chl- $a$, with a slope of 0.85 and negative intercept of 0.13 . The RMSE is 0.25 and the Chl-a-calibrated fluorescence values are, in general, slightly underestimated, with a negative median RPD of $-4.49 \%$. The coefficient of determination is $r^{2}=0.72$ and the median APD is $32.89 \%$.

For gaussian profiles (red open circle), the slope of Chl- $a$ calibrated fluorescence values is 0.83 with intercept $\sim-0.18$ and RMSE $\sim 0.24$. The Chl- $a$-calibrated fluorescence values are underestimated with a negative median RPD of $-9.46 \%$. The coefficient of determination is of $r^{2}=0.70$ and the me- dian APD is $33.69 \%$. For sigmoid profiles (blue open triangle on Fig. 12), the slope of Chl- $a$-calibrated fluorescence values is 0.44 with negative intercept of -0.13 and coefficient of determination $r^{2} \sim 0.45$. The RMSE $\sim 0.26$ and Chl- $a$-calibrated fluorescence values are overestimated with a positive median RPD of $9.42 \%$. The median APD is $30.22 \%$.

\section{Conclusions and perspectives}

A fluorescence profile measurement delivers in real-time and at very high $(\sim 1 \mathrm{~m})$ resolution a proxy of the vertical distribution of Chl- $a$. This has to be compared with the vertical resolution permitted by HPLC, one order of magnitude lower ( $\sim 10$ samples taken over a $\sim 100 \mathrm{~m}$ layer) and the time required for sampling $(1-2 \mathrm{~h})$ and laboratory analysis $(\sim 1$ day). However, fluorescence is not the perfect proxy for Chl- $a$, and therefore HPLC is preferred for the most accurate measurements.

Here, we proposed a method to reconcile the two approaches, trying to keep the advantages of both, with the specific and declared aim to obtain extended highly vertically resolved and relatively accurate Chl- $a$ profiles.

Most sensors are more or less factory-calibrated. These calibrations rely on pure Chl- $a$ or on phytoplankton cultures, which are generally not very representative of in situ phytoplankton communities with their own light and nutrient history. Some complementary HPLC measurements have sometimes been carried out for additional calibration, but this is, unfortunately, not the routine. Consequently, most fluorescence data are not fully exploited.

Our approach was first to evaluate if some information on the shape of vertical fluorescence can be used to constrain this profile into more quantitative terms, i.e. in Chl- $a$ equivalents. 

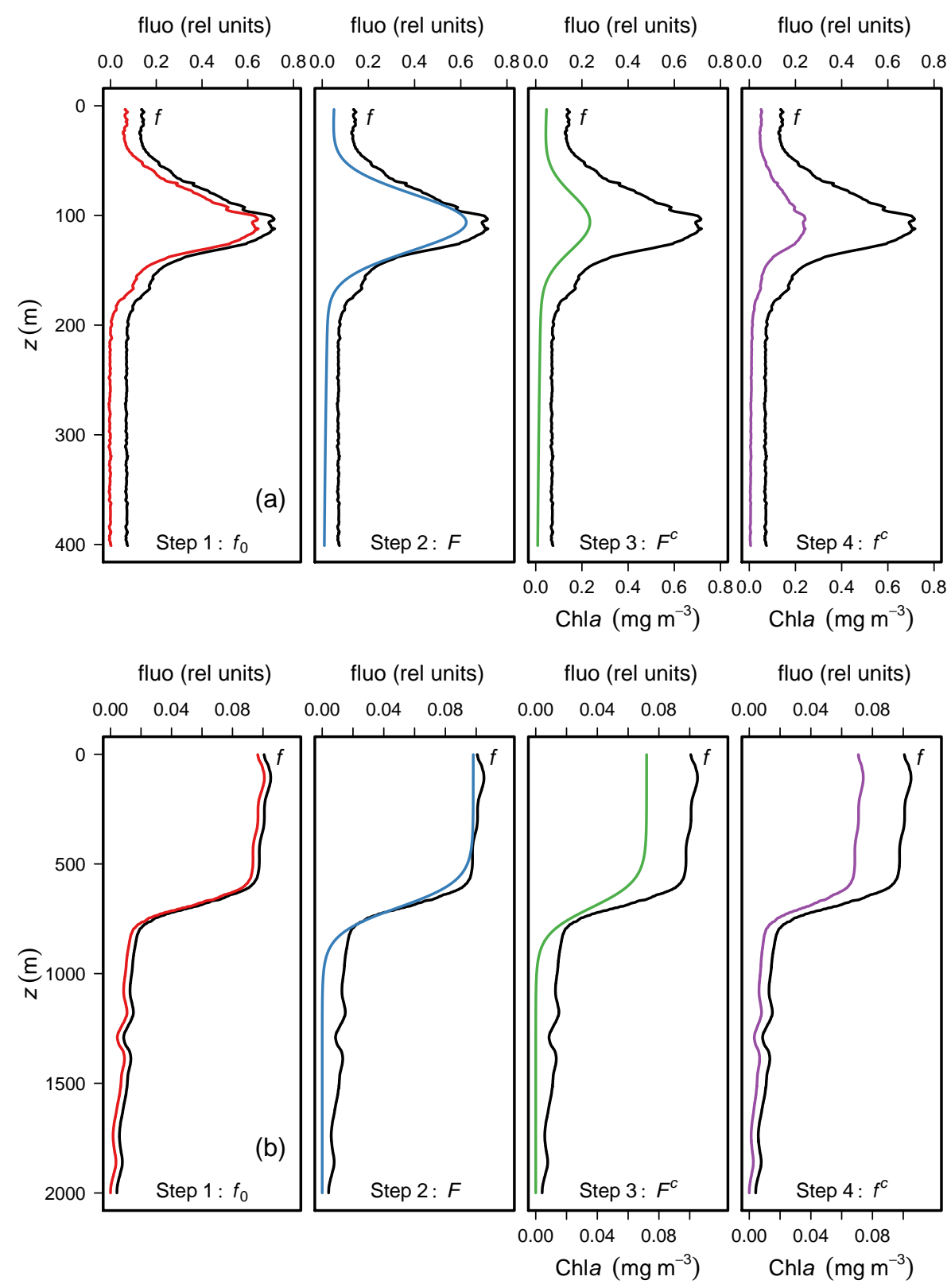

Fig. 10. The four steps of the calibration method for (a) gaussian profiles, (b) sigmoid profiles. Step1: the raw fluorescence profile $f(z)$ (black curve) is set to 0 at the bottom, the resulting profile is $f_{0}(z)$ (red curve). Step 2: $f_{0}(z)$ is fitted by the appropriate parameterization (Eqs. 2 and 3), which give $F(z)$ (blue curve). Note that for both steps, the profiles are in relative units. Step 3: $F(z)$ is calibrated in Chl- $a$ units $\left(\mathrm{mg} \mathrm{m}^{-3}\right), F^{c}(z)$ (green curve). Step 4: $f^{c}(z)$ is the Chl- $a$-calibrated fluorescence profile $\left(\mathrm{mg} \mathrm{m}^{-3}\right)$ (purple curve).

The main conclusion of the present study is that relationships do exist between descriptors of the profile shape and Chl- $a$. These relationships can be used in return to retrieve the Chl-a-calibrated fluorescence profile, without any other external information or data. This method is selfsufficient, as it does not require any additional ancillary variables (e.g. CTD, radiometric profile (Xing et al., 2011), satellite Chl- $a$ estimations, Boss et al., 2008).
The method proposed here relies on a dataset which covers a large range of trophic conditions from the hyperoligotrophic waters of the South Pacific Gyre to the eutrophic waters of the Benguela upwelling. For given trophic conditions, a certain "natural" variability characterizes the relationship between the depth-dependent shape parameters and the Chla concentration. It was not the purpose of this study to analyze the sources of this variability (except for the specific 


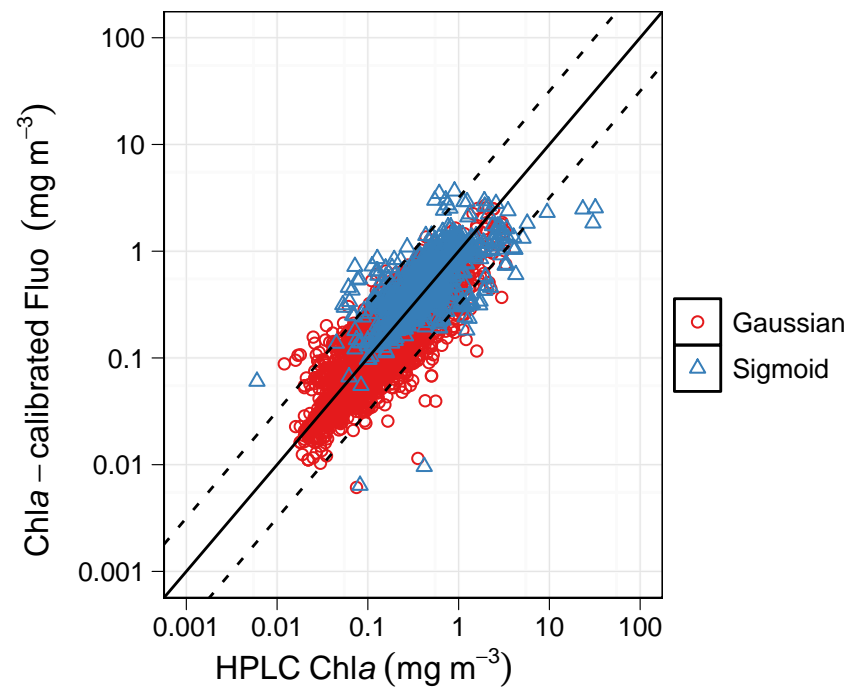

Fig. 11. Scatterplot of HPLC Chl- $a\left(\mathrm{mg} \mathrm{m}^{-3}\right)$ versus Chl- $a$ calibrated fluorescence $\left(\mathrm{mg} \mathrm{m}^{-3}\right)$ above $Z_{\mathrm{e}}$. The values derive from the 10 -fold cross validation on the original dataset. Red open circle for gaussian profiles and blue open triangle for sigmoid profiles. The plain line is the line 1:1. The dashed lines are the lines $1: 2$ and 2:1.

and well-identified case of fluorescence quenching). As a consequence, the parameterization proposed here, is only of global relevance, smilarity to the Uitz et al. (2006) parameterization.

Finally, the robustness of the relationship between shape and concentration may be a practical means to reconcile and harmonize datasets from various origins in a common currency, Chl- $a$ concentration. As such it will have the potential to help producing large and coherent calibrated Chl- $a$ profile datasets by merging past data acquired using ship-deployed fluorescence sensors to future profiles that will mostly be acquired through sensors carried by autonomous platforms (Claustre et al., 2010b).

Acknowledgements. We warmly thank the PIs and the crew of the various cruises where the Chl- $a$ and fluorescence data analyzed in the present study has been collected.We express our gratitude to Patrick Chang for the English correction. We also grateful to Rodney Forster and an anoynmous reviewer for their helpful comments and suggestions. Alexandre Mignot is funded through a grant provided by the French space agency "Centre National d'Etude Spatiale" (CNES) and the French research institute for exploration of the sea "Institut Français de Recherche pour l'Exploitation de la Mer" (IFREMER). This paper represents a contribution to the remOcean project (remotely sensed biogeochemical cycles in the Ocean), funded by the European Research Council.

Edited by: K. Suzuki

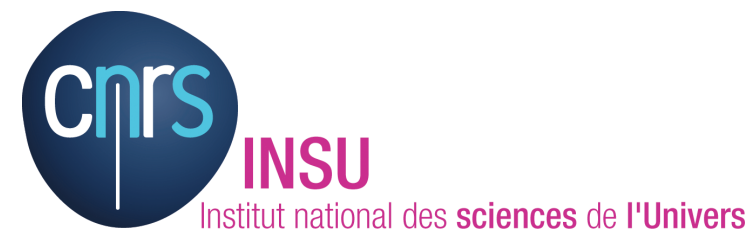

The publication of this article is financed by CNRS-INSU.

\section{References}

Antoine, D., André, J. M., and Morel, A.: Oceanic primary production: II. Estimation at global scale from satellite (Coastal Zone Color Scanner) chlorophyll, Global Biogeochem. Cy., 10, 57-69, 1996.

Behrenfeld, M. J.: Abandoning Sverdrup's critical depth hypothesis on phytoplankton blooms, Ecology, 91, 977-989, 2010.

Boss, E., Swift, D., Taylor, L., Brickley, P., Zaneveld, R., Riser, S., Perry, M. J., and Strutton, P. G.: Observations of pigment and particle distributions in the western North Atlantic from an autonomous float and ocean color satellite, Limnol. Oceanogr., 53, 2212-2122, 2008.

de Boyer Montégut, C., Madec, C., Fischer, A. S., Lazar, A., and Ludicone, D.: Mixed layer depth over the global ocean: An examination of profile data and a profile-based climatology, J. Geophys. Res., 109, C12003, doi:10.1029/2004JC002378, 2004.

Campbell, J. W.: The lognormal distribution as a model for bio-optical variability in the sea, J. Geophys. Res., 100, C7, doi:10.1029/95JC00458, 1995.

Claustre, H., Kerhervé, P., Marty, J. C., Prieur, L., Videau, C., and Hecq, J. H .: Phytoplankton distribution associated with a geostrophic front: Ecological and biogeochemical implications, J. Mar. Res., 52, 711-742, 1994.

Claustre, H. and Marty, J.: Specific phytoplankton biomass and their relation to primary production in the tropical NorthAtlantic, Deep-Sea Res. Pt. I, 42, 1475-1493, 1995.

Claustre, H., Morel, A., Babin, M., Cailliau, C., Marie, D., Marty, J.-C., and Vaulot, D.: Variability in particle attenuation and stimulated fluorescence in the tropical and equatorial Pacific: scales, patterns and some biogeochemical implications, J. Geophys. Res., 104, 3401-3422, 1999.

Claustre, H., Fell, F., Oubelkheir, K., Prieur, L., Sciandra, A., Gentili, B., and Babin, M.: Continuous monitoring of surface optical properties across a geostrophic front: Biogeochemical inferences, Limnol. Oceanogr., 45, 309-321, 2000.

Claustre, H., Hooker, S. B., Van Heukelem, L., Berthon, J. F., Barlow, R., Ras, J., Sessions, H., Targa, C., Thomas, C. S., van der Linde, D., and Marty, J. C.: An intercomparison of HPLC phytoplankton methods using in situ samples: Application to remote sensing and database activities, Mar. Chem., 85, 41-61, 2004.

Claustre, H., Merien, D., Ras, J., Prieur, L., Dallot, S., Prasil, O., Dousova, H., and Moutin, T.: Toward a taxon-specific parameterization of bio-optical models of primary production: A case study in the North Atlantic, J. Geophys. Res., 110, C7, doi:10.1029/2004JC002634, 2005.

Claustre, H., Bishop, J., Boss, E., Steward, B., Berthon, J. F., Coatanoan, C., Johnson, K., Lotiker, A., Ulloa, O., Perry, M. J., D'Ortenzio, F., Hembise Fanton D'Andon, O., and Uitz, J.: Bio-optical profiling floats as new observational tools for 
biogeochemical and ecosystem studies, in: Proceedings of the "OceanObs'09: Sustained Ocean Observations and Information for Society" Conference (Vol. 2), Venice, Italy, 21-25 September 2009, edited by: Hall, J., Harrison, D. E., and Stammer, D., ESA Publication WPP-306, doi:10.5270/OceanObs09.cwp.17, 2010a.

Claustre, H., Antoine, D., Boehme, L., Boss, E., D’Ortenzio, F., Fanton D'Andon, O., Guinet, C., Gruber, N., Handegard, N. O., Hood, M., Johnson, K., Körtzinger, A, Lampitt, R., LeTraon, P. Y., Lequéré, C., Lewis, M., Perry, M. J., Platt, T., Roemmich, D., Sathyendranath, S., Testor, P., Send, U., and Yoder, J.: Guidelines towards an integrated ocean observation system for ecosystems and biogeochemical cycles, in: Proceedings of the "OceanObs'09: Sustained Ocean Observations and Information for Society" Conference (Vol. 1), Venice, Italy, 21-25 September 2009, edited by: Hall, J., Harrison, D. E., and Stammer, D., ESA Publication WPP-306, doi:10.5270/OceanObs09.pp.14, 2010 b.

Crombet, Y., Leblanc, K., Quéguiner, B., Moutin, T., Rimmelin, P., Ras, J., Claustre, H., Leblond, N., Oriol, L., and Pujo-Pay, M.: Deep silicon maxima in the stratified oligotrophic Mediterranean Sea, Biogeosciences, 8, 459-475, doi:10.5194/bg-8-4592011, 2011.

Cullen, J. J.: The Deep Chlorophyll Maximum-Comparing vertical profiles of Chlorophyll- $a$, Can. J. Fish. Aquat. Sci., 39, 791-803, 1982.

Cullen, J. J. and Lewis, M. R.: Biological processes and optical measurements near the sea-surface: some issues relevant to remote sensing, J. Geophys. Res., 100, 13, doi:10.1029/95JC00454, 1995.

D’Ortenzio, F.,Thierry, V., Eldin, G., Claustre, H., Testor, P., Coatanoan, C., Tedetti, M., Guinet, C., Poteau, A., Prieur, L., Lefevre, D., Bourrin, F., Carval, T., Coutx, M., Garçon, V., Thouron, D., Lacombe, M., Lherminier, P., Loisel, H., Mortier, L., and Antoine, D.: Oceanic Autonomous Platforms for Biogeochemical Studies: Intrumentation and measure, http://www. obs-vlfr.fr/OAO/file/PABIM_white_book_version1.3.pdf, February 2010.

Ediger, D. and Yilmaz, A.: Characteristics of deep chlorophyll maximum in the Northeastern Mediterranean with respect to environmental conditions, J. Mar. Res., 9, 291-303, 1996.

Estrada, M., Marrase, C., Latasa, M., Berdalet, E., Delgado, M., and Riera, T.: Variability of deep chlorophyll maximum characteristics in the Northwestern Mediterranean, Mar. Ecol-Prog. Ser., 92, 289-300, 1993.

Freeland, H. J., Roemmich, D., Garzoli, S. L., Le Traon, P. Y., Ravichandran, M., Riser, S., Thierry, V., Wijffels, S., Belbéoch, M., Gould, J., Grant, F., Ignazewski, M., King, B., Klein, B., Mork, K. A., Owens, B., Pouliquen, S., Sterl, A., Suga, T., Suk, M. S., Sutton, P., Troisi, A., Vélez-Belchi, P. J., and Xu, J.: Argo a decade of progress, in: Proceedings of the "OceanObs'09: Sustained Ocean Observations and Information for Society" Conference (Vol. 1), Venice, Italy, 21-25 September 2009, edited by: Hall, J., Harrison, D. E., and Stammer, D., ESA Publication WPP-306, 2010.

Gregg, W. W. and Conkright, M.: Decadal changes in global ocean chlorophyll, Geophys. Res. Lett., 29, 15, doi:10.1029/2002GL014689, 2002.

Herbland, A. and Voituriez, B.: Hydrological Structure-Analysis for estimating the primary production in the Tropical Atlantic Ocean, J. Mar. Res., 37, 87-101, 1979.
Hidalgo-Gonzalez, R. M. and Alvarez-Borrego, S.: Chlorophyll profiles and the water column structure in the Gulf of California, Oceanol. Acta, 24-1, 19-28, 2001.

Hodges, B. A. and Rudnick, D. L.: Simple models of steady state deep maxima in chlorophyll and biomass, Deep-Sea Res. Pt. 1, 51, 999-1015, 2004.

Holm-Hansen, O., Amos, A. F., and Hewes, C. D.: Reliability of estimating Chlorophyll- $a$ concentrations in Antarctic waters by measurement of in situ Chlorophyll- $a$ fluorescence, Mar. EcolProg; Ser., 196, 103-110, 2000.

Hooker, S. B., Van Heukelem, L., Thomas, C. S., Claustre, H., Ras, J., Barlow, R., Sessions, H., Schlüter, L., Trees, C., Stuart, V. Head, E., Clementson, L., Fishwick, J., Llewellyn, C., Aiken, J.: The second Seawifs HPLC analysis round-robin experiment (SeaHARRE-2), NASA Tech. Memo., 2005-212785, NASA Goddard Space Flight Center, Greenbelt, Maryland, 112 pp., 2005.

Hooker, S. B., Van Heukelem, C. S., Thomas, H., Claustre, H., Ras J., Schlüter, L., Perl, J.,Trees, C., Stuart, V., Head, E., Barlow, R., Sessions, H., Clementson, L., van der Linde, D., Eker-Develi, E., Berthon, J. F., and Ismails, H.: The Third SeaWifs HPLC Analysis Round-Robin Experiment (SeaHARRE3), NASA Tech. Memo., 2009-215849, NASA Goddard Space Flight Center, Greenbelt, Maryland, 97 pp., 2009.

Lewis, M. R., Cullen, J. J., and Platt, T.: Phytoplankton and Thermal Structure in the Upper Ocean: Consequences of Nonuniformity in Chlorophyll Profile, J. Geophys. Res., 88, C4, doi:10.1029/JC088iC04p02565, 1983.

Lorenzen, C. J.: A method for the continuous measurement of in vivo chlorophyll concentration, Deep-Sea Res., 13, 223-227, 1966.

Mann, K. H. and Lazier, J. R. N.: Dynamics of Marine Ecosystems: Biological-Physical Interactions in the Oceans, 3. Edn., WileyBlackwell Publication, Oxford, 1996.

Mantyla, A. W., Bograd, S. J., and Venrick, E. L.: Patterns and Controls of chlorophyll- $a$ and primary productivity cycles in the Southern California Bight, J. Mar. Syst., 73, 48-60, 2008.

Marty, J. C., Chiaverini, J., Pizay, M. D., and Avril, B.: Seasonal and interannual dynamics of nutrients and phytoplankton pigments in the western Mediterranean Sea at the DYFAMED timeseries station (1991-1999), Deep-Sea Res. Pt. II, 49, 1965-1985, 2002.

Morel, A. and Berthon, J. F.: Surface pigments, algal biomass profiles, and potential production of the euphotic layer: Relationships reinvestigated in view of remote-sensing applications, Limnol. Oceanogr., 34, 1545-1562, 1989.

Morel, A. and Maritorena, S.: Bio-optical properties of oceanic waters: A reappraisal, J. Geophys. Res., 106, C4, doi:10.1029/2000JC000319, 2001.

Morel, A., Gentili, B., Chami, M., and Ras, J.: Bio-optical properties of high chlorophyll Case 1 waters and of yellow-substancedominated Case 2 waters, Deep-Sea Res., 53, 1439-1459, 2006.

Niewiadomska, K., Claustre, H., Prieur, L., and D'Ortenzio, F.: Submesoscale physical-biogeochemical coupling across the Ligurian current (northwestern Mediterranean) using a bio-optical glider, Limnol. Oceanogr., 53, 2210-2225, 2008.

Platt, T., Sathyendranath, S., Caverhill, C. M., and Lewis, M. R.: Ocean primary production and available light: further algorithms for remote sensing, Deep-Sea Res., 35, 855-879, 1988. 
$\mathrm{R}$ development Core team: $\mathrm{R}$ a Language and environnement for statistical computing (http://www/r-project.org), R Foundation for Statistical Computing, Vienna, Austria, 2010.

Ras, J., Claustre, H., and Uitz, J.: Spatial variability of phytoplankton pigment distributions in the Subtropical South Pacific Ocean: comparison between in situ and predicted data, Biogeosciences, 5, 353-369, doi:10.5194/bg-5-353-2008, 2008.

Richardson, A. J., Silulwane, N. F., Mitchell-Innes, B. A., and Shillington, F. A.: A dynamic quantitative approach for predicting the shape of phytoplankton profiles in the ocean, Progr. Oceanogr., 59, 301-319, 2003.

Roemmich, D., Boehme, L., Claustre, H., Freeland, H., Fukasawa, M., Goni, G, Gould, W. J, Gruber, N., Hood, M., Kent, E., Lumpkin, R., Smith, S., and Testor, P.: Integrating the ocean observing system: mobile platforms, in: Proceedings of the “OceanObs'09: Sustained Ocean Observations and Information for Society" Conference (Vol. 1), Venice, Italy, 21-25 September 2009, edited by: Hall, J., Harrison, D. E., and Stammer, D., ESA Publication WPP-306, doi:10.5270/OceanObs09.pp.33, 2010.

Sackmann, B. S., Perry, M. J., and Eriksen, C. C.: Seaglider observations of variability in daytime fluorescence quenching of chlorophyll- $a$ in Northeastern Pacific coastal waters, Biogeosciences Discuss., 5, 2839-2865, doi:10.5194/bgd-5-2839-2008, 2008.

Steele, J. H. and Menzel, D. W.: Conditions for maximum primary production in the mixed layer, Deep-Sea Res., 9, 39-49, 1962.

Uitz, J., Claustre, H., Morel, A., and Hooker, S. B.: Vertical distribution of phytoplankton communities in open ocean: An assessment based on surface chlorophyll. J. Geophys. Res., 111, C08005, doi:10.1029/2005JC003207, 2006.
Uitz, J., Claustre, H., Griffiths, F. B., Ras, J., Garcia, N., and Sandronie, V.: A phytoplankton class-specific primary production model applied to the Kerguelen Islands region (Southern Ocean), Deep-Sea Res. Pt. I, 56, 541-560, 2009.

Varela, R. A., Ramiro, A., Cruzado, A., Tintore, J., and Garda Ladona, E.: Modeling the deep-chlorophyll maximum: A coupled physical-biological approach, J. Mar. Res., 50, 441-463, 1992.

Vidussi, F., Claustre, H., Bustillos-Guzmàn, J., Cailliau, C., and Marty, J. C.: Determination of chlorophylls and cartenoids of marine phytoplankton: separation of Chlorophyll- $a$ from divinylChlorophyll- $a$ and zeaxanthin from lutein, J. Plankton Res., 18, 2377-2382, doi:10.1093/plankt/18.12.2377, 1996.

Ward, B. A. and Waniek, J. J.: Phytoplankton growth conditions during autumn and winter in the Irminger Sea, North Atlantic, Mar. Ecol. Prog. Ser., 334, 47-61, 2007.

Xing, X., Morel, A., Claustre, H., Antoine, D., D’Ortenzio, F., Poteau, A., and Mignot, A.: Combined processing and mutual interpretation of radiometry and fluorimetry from autonomous profiling Bio-Argo floats, J. Geophys. Res., 116, C06020, doi:10.1029/2010JC006899, 2011.

Yacobi, Y. Z., Zohary, T., Kress, N., Hecht, A., Robarts, R. D., Waiser, M., Wood, A. M., and Li, W. K. W.: Chlorophyll distribution throughout the southeastern Mediterranean in relation to the physical structure of the water mass, J. Mar. Syst., 6, 179190, 1995. 